\title{
Social Change and its Potential Impacts on Chinese Population Health
}

\author{
Hong Wang
}

\section{Introduction}

This chapter aims to analyze the relationship between social change and the population's health by presenting a case study of that relationship from the People's Republic of China (China). With a territory of 9.6 million square kilometers, it is ranked the third largest country in the world. It's population reached 1.25 billion in the year 2000, which ranks it the first in the world. ${ }^{1}$

China is considered one of few Socialist States in the world. Administratively, China is divided into 23 provinces (including Taiwan), 5 autonomous regions, 2 special administration regions, and 4 municipalities. ${ }^{2}$ The government structure from the top to the bottom includes the Central Government, Provincial Government, Prefecture and City Government, District (in the urban area)/County (in the rural area) Government, and Resident Street (in the urban area)/ Township (in the rural area) Government. Although the Neighborhood Committee (in the urban area)/ the Village Committee (in the rural area) also plays administration roles at the bottom, below the resident street/ township government. It is considered, as the extension, not the formal entity within the government structure.

Within the past 25 years, China has experienced transformation of its economic system from a highly centralized planned economy toward a market oriented economic system. This process has led to massive and rapid changes in all aspects of society with profound effects on the population's health in the large parts of the country. Along with the material prosperity, the living conditions of Chinese people, such as food, shelter, and sanitation status, have been improving steadily. People have more capability to purchase health related merchandise as well as health

1 Atlapedia (2002). People's Republic of China, www.atlapedia.com/online/ countries/china.htm.

2 Statistical Yearbook, (2000). 
services. Overall the health status of most Chinese has improved but there are significant exceptions to this overall conclusion. These exceptions arise from increasing inequity of income, increases in unemployment rates, the decline of health insurance coverage, changes in demography, changes in social value, culture, health related behaviors, and the changes of health care systems.

This chapter is organized into five sections. The introduction section provides the background information including a brief summary of China's geographic and administration system and also the purpose of this case study. Section II, provides an overview of China's economic reform. Section III describes the major social changes brought on by this economic reform that have potentially both positive and negative influences on the population's health status. Section IV describes the current Chinese population health status, which reflect the mixed impacts by the economic and social change process. Then finally the policy implications and suggestions will be included in the last section $\mathrm{V}$.

\section{The Recent Economic Reforms in China}

\section{The Background of Chinese Economic Reform}

Before 1979, the Chinese economy was organized on a central planning system. Under this system, most resources, such as goods, services and information, were produced and allocated as collective goods. ${ }^{3}$ In urban areas, the allocation of labor to working units and enterprises was administratively determined through provincial and local labor bureaus. The assignment of individuals to the working units and enterprises reflected administrative goals, rather than individual or working unit's need and preference. ${ }^{4}$ Almost all those of working age were guaranteed to get permanent jobs in the state-owned or collective-owned working units or enterprises. ${ }^{5}$ The wage of the employees was set at a very low level by the government based on the working years, position, occupation, and education to meet basic needs for food and clothing with little variation. In addition, the working unit or enterprise was also responsible for providing welfare to its

3 A. Oberschall, 'The Great Transition: China, Hungary, and Sociology Exit Socialism into the Market', American Journal of Sociology, 101(4) (1996), 1028-41.

4 D. P. Coacy and L. Wang, 'Equity, Efficiency, and Labor-Market Reforms in Urban China: The Impact of Bonus Wages on the Distribution of Earnings', China Economic Review, 11 (2000), 213-231.

5 C. Fang,, X. Zhang, et al., 'Emergence of Urban Poverty and Inequality in China: Evidence from Household Survey', China Economic Review, 13 (2002), 430-443. 
employees, which includes housing, healthcare, childcare, pensions and certain subsidized foods. Labor mobility across different working units and enterprises was tightly controlled and extremely infrequent. ${ }^{6}$

In rural areas, the farmland was owned by the state with farmers working collectively in the commune system. The government set very low prices for agricultural products. Farmers' earnings were quite equal but only sufficient enough to survive. ${ }^{7}$ The commune system also provided certain welfare to the farmers, such as healthcare and child education.

Although Chinese government achieved its equalization goals under the central planning system described above, the productivity and efficiency of whole society was very low due to the lack of incentives and responsibilities. In addition, the continuing political movements, nature disasters, and international isolation severely distorted the Chinese economic development. By the end of culture revolution in 1976, China was still one of the poorest countries in the world.

Under the planning system, the government revenue is mainly from profitable state-owned and collective-owned enterprises. ${ }^{8}$ Because of low efficiency and low productivity, many of these enterprises were losing money and required government subsidies. By the end of 1998, the government deficit reached to 13.5 billion Yuan, which are about $11.8 \%$ of the government revenue.'

\section{The Major Approaches of Economic Reform}

Once Xiaoping Deng took power in China in 1978, he launched the most recent economic reform, to transform the central planning economic system to a market oriented economic system and to modernize China in terms of its industry, agriculture, science and technology, and national defense system.

The economic reform was initiated by reforming the rural economy system. The collective economy was then replaced by the individual household responsibility system in the early 1980s. The financial incentive was that the farmers could receive direct economic rewards from individual productivity. The farmland was divided into small plots still under the ownership of the state. Each family makes a contract for its plot, agreeing to produce a certain quota of crops, which the state purchases

6 Coacy and Wang, (2000).

7 R. Zhang and M. S. Tam, 'Changes in Income Distributions in China in the Process of Economic Reform in the 1980s: A Welfare Approach', China Economic Review 2(1) (1991), 97114 .

8 R. S. Eckaus, 'Some Consequences of Fiscal Reliance on Extrabudgetary Revenues in China', China Economic Review, 14 (2003), 72-88.

9 Y. Zhang, and F. He, 'System Transition Induced by Fiscal Pressure', From Planning Economy to Market Economy (Beijing, China Finance Publish House, 1998). 
at a relatively low fixed price. Then any output that exceeds the quota can be sold to the state or in the market at a higher bonus price. ${ }^{10}$ In order to encourage farmers to increase their productivity and to increase the farmer's income, the government also increased the purchasing price of agriculture products while reducing the prices of agriculture production materials. These measures have succeeded dramatically.

Urban economic reform was introduced in the mid 1980s. Decentralization of government power (including decisions concerning resource allocation and renumeration) to working units and enterprises was an important feature. The enterprise manager was given greater autonomy in recruiting, dismissing, promoting and reallocating their employees. The bonus wage was introduced on top of the previous fixed standard wage, and was directly linked to an individual's productivity and enterprise performance. ${ }^{11}$

The second key element of the reform was to allow private, individual, and foreign-owned enterprises to compete with state-owned enterprises. In 1978, there were virtually no private-owned, and foreign-owned enterprises. Seventy eight percent of industrial production was from state-owned enterprises with the rest from collective-owned enterprises. By 1999, 44\% of industrial production was from private, foreign and joint-owned enterprises and only $28.2 \%$ from state owned enterprises. $^{12}$

Welfare reform started in 1996 with the aim of reducing the heavy burdens of welfare and to increase market competition. The central theme of this reform was to transfer welfare provision obligation, such as health care and housing, from enterprises to social insurance agencies and to individuals. This welfare system reform also reduced the employees' welfare ties with their employers and increased employees' mobility to change jobs and achieve higher earning potential. ${ }^{13}$

The Chinese government also established a series of special economic zones and opened its door to the world to increase the international trade and foreign investments, and to acquire advanced technology and management knowledge. The total value of import-export increased from 20.6 billion US dollars in 1978 to 474.3 billion US dollars in $2000 .^{14}$

During the 1980s the central government also decentralized its fiscal system and implemented the "provincial contracting' system, which allows provinces to

10 W. C. Hsiao, 'Transformation of Health Care in China', $N$ Eng J Med., 310 (1984), 932-326.

11 Cacy and Wang (2000).

12 China Statistical Bureau, China Statistical Yearbook 1997 (Beijing, China Statistical Publishing House, 1998) and China Statistical Bureau, China Statistical Yearbook 1999 (Beijing, China Statistical Publishing House, 2000).

13 Fang, Zhang et al., (2002).

14 G. Long, 'The Opportunities and Challenges to the Policy of "Open the Door to the Outside” under the Globalization', The New Stage of China Economy (2002). 
contract with the central government for a fixed revenue sharing quota: a base quota of shared revenues must be transferred to the central government, but all the revenues above this quota may be kept by the province. The shares of local government revenues in the total government revenues are between $60-85 \%$ during 1978-1993..$^{15}$ After implementing this financial reform, the financial status of local government has improved. Local governments have more motivation and capability to develop regional economy. ${ }^{16}$ The second major government finance system reform was conducted in 1994. This reform separated the taxation system into central and local government taxations. The share of central government revenue in total government revenue has increased from $22 \%$ in 1993 to $56 \%$ in $1994^{17}$, which significantly increased the central government's capability to cross-subsidy between rich and poor areas.

\section{Health Related Social Changes Brought on by the Economic Reform}

After the Economic Reform was initiated in 1978, the Chinese economy achieved impressive results in terms of both real GDP and per capita income. This reform also led to dramatic changes in living conditions, better education, improvements in nutrition, housing, and sanitation.

\section{Economic Development}

China's economy has grown dramatically since the economic reform in 1978. The average annual increase of the Gross Domestic Product (GDP) was 9.7\% during 1978-1999 based on the index of GDP at comparable price, which is 3.2 percent point faster than the annual increase rate of the GDP before the economic reform during 1952-1977. After considering the factor of population increase, the average annual increase per capita GDP was 8.3\% during 1978-1999 based on the index of per capita GDP at comparable price, which is twice as fast as the increases during 1952-1977 period (Figure 1).

15 H. Sheng, 'The Relationship between Fiscal System Reform and the Stability of Macro-Economy', Market and Stability (S. Zhang, 2001).

16 C. M. Grogan, 'Urban Economic Reform and Access to Health Care Coverage in the People's Republic of China', Soc. Sci. Med, 41(8) (1995), 1073-1084.

17 Sheng, (2001). 
Figure 1. Per capita GDP at comparable price, 1952-1999.

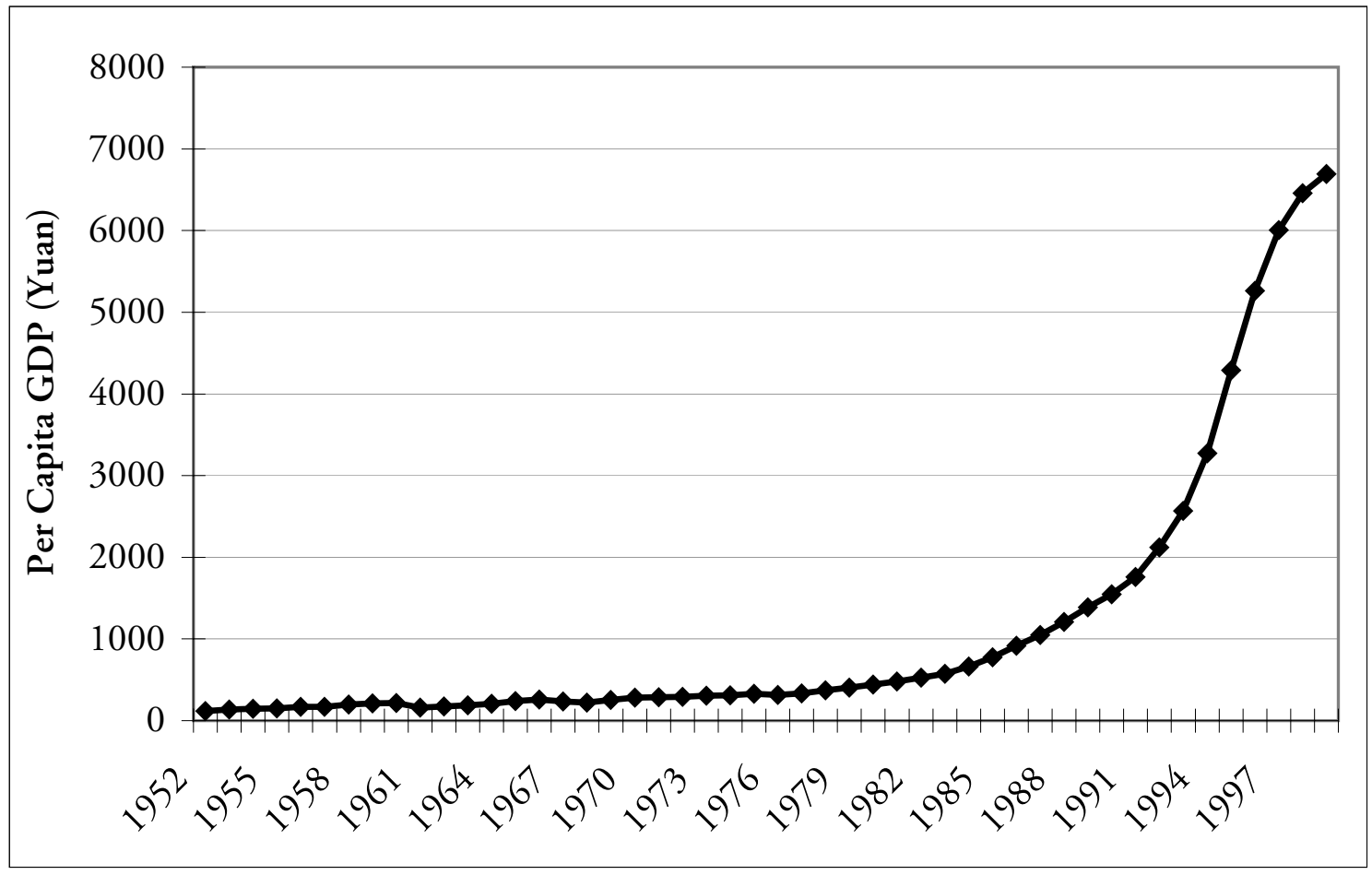

Source: China Statistical Yearbook 2000, China Statistical Bureau.

The economic prosperity provided the premise for improving population living conditions. Food expenditure (as a proportion of total expenditure) declined from $57.5 \%$ in 1978 to $39.2 \%$; it declined by about $18 \%$ for both urban and rural population (Figure 2). People had more capacity to consume other goods such as education and health services to improve the quality of life. 
Figure 2. Percentage of food consumption in total consumption in rural and urban China 1978-2000.

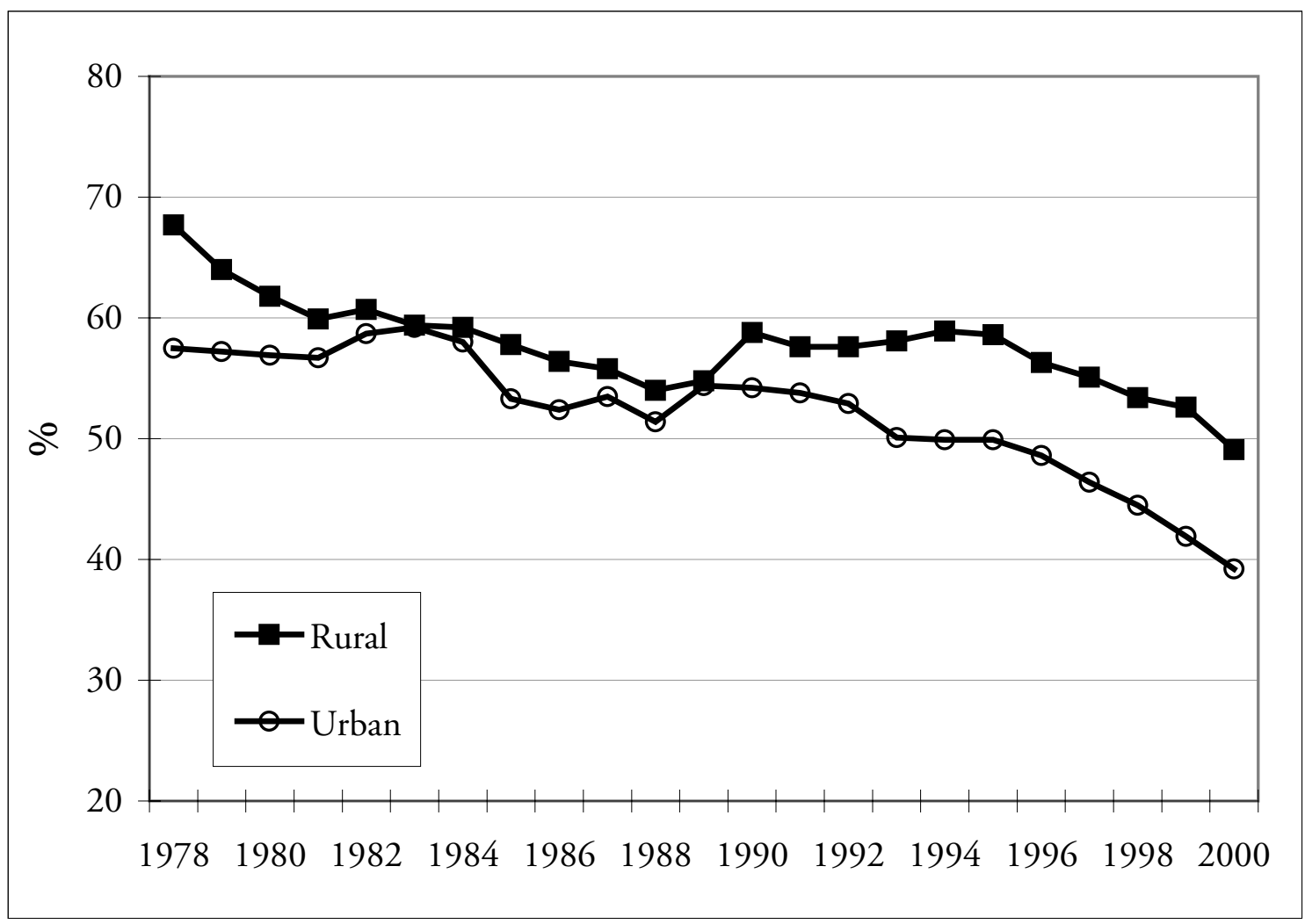

Source: China Statistical Yearbook 2001, China Statistical Bureau.

\section{Education, Housing, and Nutrition}

Based on the population census data, the illiteracy rate declined from $22.9 \%$ in 1982 to $6.7 \%$ in 2000 . The proportion of the population who had college or higher education increased from $0.6 \%$ in 1982 to $2.9 \%$ in 2000 (Figure 3). The percentage of college students in the schools increased from $8.9 \%$ in 1978 to $46.0 \%$ in 2000 . $^{18}$ It is expected that higher education would lead to better health status. ${ }^{19}$

18 China Statistical Bureau, China Statistical Yearbook 2000 (Beijing, China Statistical Publishing House, 2001).

19 P. Farrel and V. R. Fuchs, 'Schooling and Health: The Cigarette Connection', Journal of Health Economics, 1 (1982), 217-230; J. K. House and J. M. Lepkowski, 'The Social Stratification of Aging and Health', Journal of Health and Social Behavior, 35 (1994), 213-234; M. Grossman, 'The Human Capital Model of the Demand for Health', Handbook of Health Economics (Cambridge, MA, National Bureau of Economic Research, Working Paper 7078, 1999). 
Figure 3. Percentage of population at educational level 1964-2000.

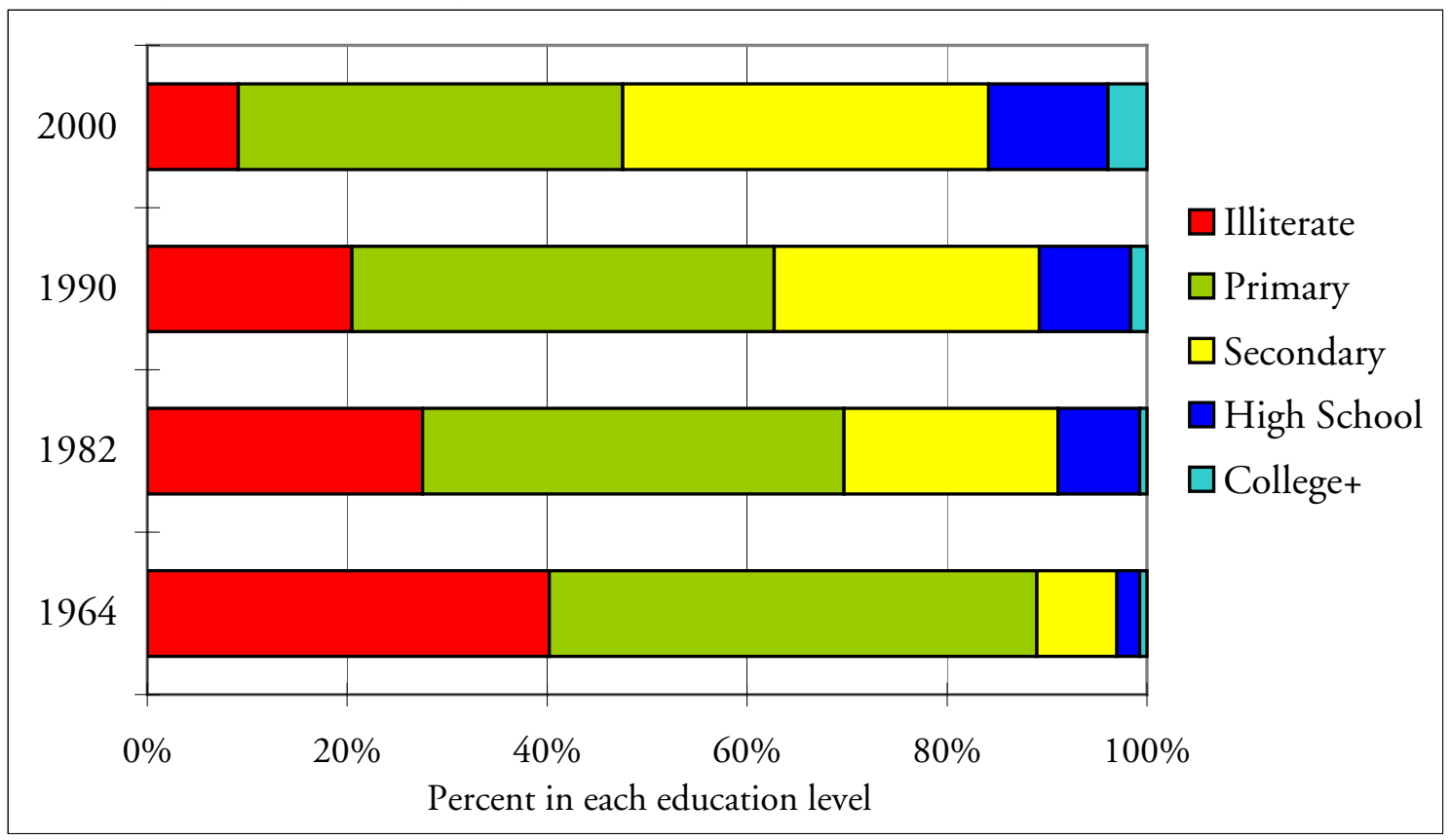

Source: China Statistical Yearbook 2001, China Statistical Bureau.

Both rural and urban areas have witnessed an extraordinary boom in house construction since 1978. In the rural area, per capita measure of housing increased from 8.1 square meters in 1978 to 24.8 square meters in 2000. In the urban area, this figure increased from 3.6 square meters to 10.3 meters. Within 23 years, the housing size per capita increased 3 times in both urban and rural areas. ${ }^{20}$ The quality of housing also improved. Many new houses in the rural area were constructed of bricks, tiles, or reinforced concrete, whereas the older stock of housing was often built of adobe walls and thatched roofs. ${ }^{21}$

With the economic growth, the Chinese nutrition status also improved. In the urban area, the consumption of grain declined to $85 \mathrm{~kg}$ per capita per years in 1999 ( $58 \%$ of the consumption in 1981). While the consumption of meats, fish, shrimps, cooking oils and eggs increased. The consumption of the rural population shared the same trends with the urban population (Table 1 in Tables). The nutrition status of the Chinese population, especially rural population, improved significantly.

20 China Statistical Bureau, China Statistical Yearbook 2000 (Beijing, China Statistical Publishing House, 2001).

21 T. Mckinley and L. N. Wang, 'Housing and Wealth in Rural China', China Economic Review, 3(2) (1992), 195-211. 


\section{Sanitation and Clean Water}

In the urban area, the percentage of the coverage of pipe water supply has been increased from $32 \%$ in 1952 to $96 \%$ in 2000 . Unlike drinking water, the human waste sanitizing rate in urban area is relatively low. Only 55\% human waste has been sanitized in 1997. It is predicted by the Ministry of Construction that by 2010, the urban pipe water coverage will reach to $100 \%$ and the human waste sanitizing rate will be $85 \%$ in urban China. ${ }^{22}$

In the rural area, nearly $55.2 \%$ of the rural population accessed the pipe water system in 2000, which is 35 percent point higher than the figure in 1987. About $44.8 \%$ of the rural households have built the toilet with the sanitizing process in $2000 .^{23}$

\section{Health Care System Development}

One year after the economic reform, China initiated its health system reform. ${ }^{24}$ Many measures that were used in other economic sectors were also adopted in the health sector - decentralizing the power of the resource allocation to health care institutes; allowing private, individual, and foreign-owned health institutes to compete with state-owned institutes; using bonus wages and rising certain services prices as the economic incentives to improve doctors productivity; and cutting operational costs of services in order to improve efficiencies. These reforms successfully solved some problems that existed in the previous system, such as the shortage of supply to meet increased health demands of the population and inefficiency due to the lack of economic incentives. The health care resources are continuing to grow, the number of health institute increased by $8.3 \%$, the number of hospital bed per 1000 population increased by $5.6 \%$, and the number of doctor per 1000 population increased $7.1 \%$ during $1978-1999 .^{25}$

Nevertheless, certain aspects of the social changes brought on by this rapid economic development have potential negative impacts on the population's health. These impacts come from the increases in distribution of income, increases in unemployment rates, changes in emography, changes in social value, culture and

$22 \mathrm{X}$. Li, 'The Trend and the Strategies of the Development of Urban basic construction.Beijing'. Minstry of Construction, www.stats-sd.gov.cn/cxjs/cjdt/csjj.htm. (1997).

23 Patriot Health Campaign Committee, 'Provincial Summaries of "Ninth Five Year Plan" and the Plans of "Tenth Five Year Plan" on Water and Toilet Improvement' (Beijing, 2002).

24 R. Peng, R. Cai, et al., China Reform: The Edition of Health System Reform (Dalian, Dalian Publishing House, 1992).

25 China Statistical Bureau, (2001). 


\section{Income Inequalities}

Figure 4. China Gini Coefficient 1978-2000.

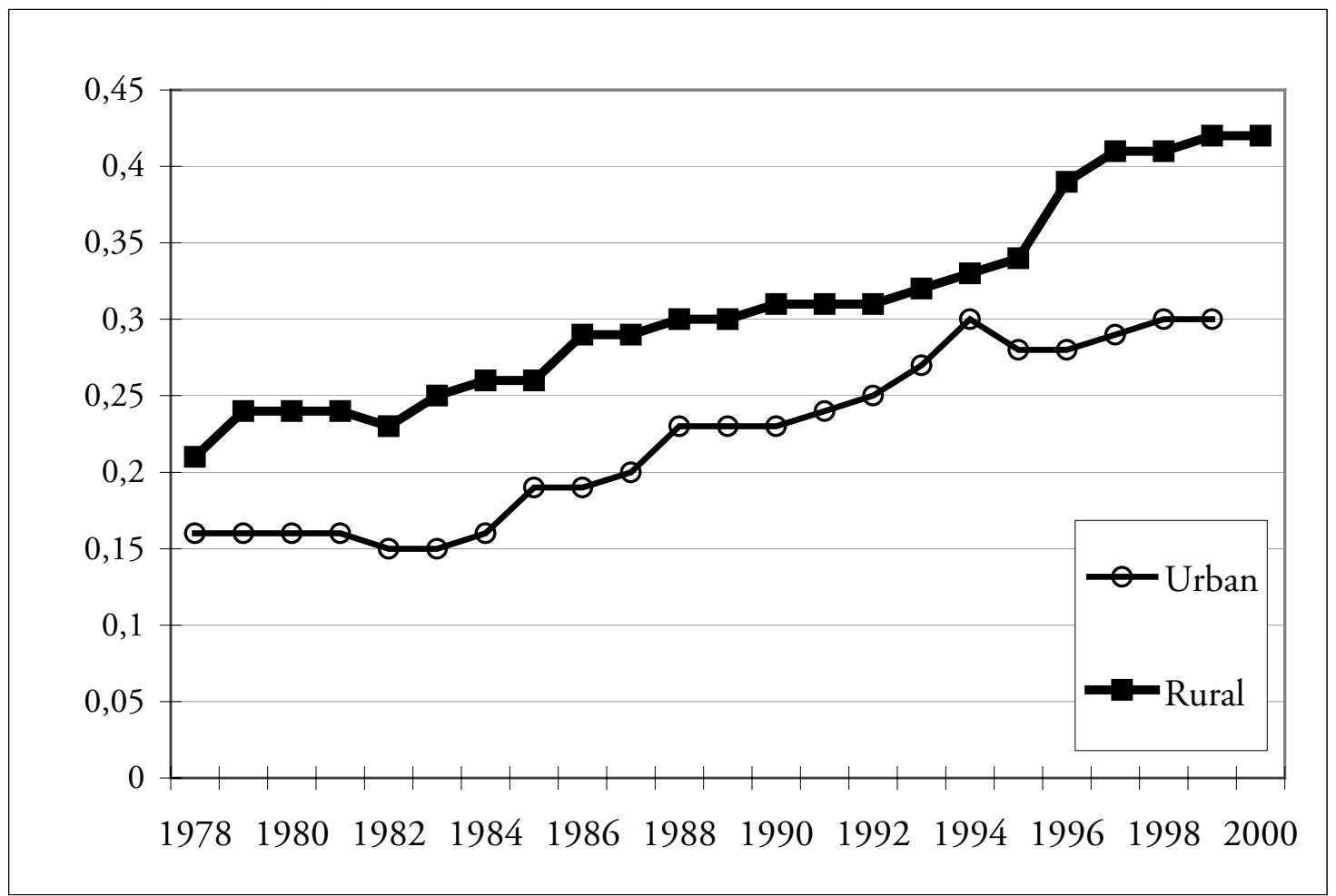

Source: Zhao and Wang 2002.

health related behaviors, the decline of health insurance coverage, and the changes of health care delivery systems.

The major critiques of the Chinese economic reforms focus on the issue of inequality. Almost two decades into the implementation of the "get rich first" policy, the Gini coefficient, the indicator that measures income inequality, increased from 0.16 in 1978 to 0.30 in 1999 in urban China, and from 0.21 in 1978 to 0.42 in 2000 in rural China (Figure 4). Per capita GDP in Shanghai is 37,382 Yuan, while it is only 2,895 Yuan in Guizhou in 2001 (Table 2 in Tables). The income gap between the urban and rural was 2.9 times different at the beginning of the economic reform this declined to 2.3 during the initiation period of the reform during 1978 and 1985, while the economic reform was mainly focused on the rural economic reform. But this gap has increased since 1986 reaching 3.5 times difference by the late 1990 s. $^{26}$

26 China Statistical Bureau, (2001). 
Research suggests that these income disparities could have had negative impacts on the distribution as well as the level of the population health status. ${ }^{27}$ The experiences from advanced economies indicate that rapid economic growth can cause critical social insecurities and health problems. Rapid economic growth has always brought serious disruption: environmental, ideological, and political. As a result the relationship between economic growth and population health is complex since such disruption always threatens to spill over into deprivation, disease and death. ${ }^{28}$ To attain a higher income, people may need to engage in occupations that have more stress and strain and greater exposure to risks. ${ }^{29}$ Rising income may also be associated with consuming adverse diets and exercising less (will be discussed in the following paragraphs), all resulting in the worse health status.

\section{Unemployment and Floating Population}

Although society became more efficient through decentralization, privatization, and market competition, the unemployment has increased. For decades, the word "unemployment' was taboo in Mainland China. In the 1980's, surplus workers from various enterprises were described as "job-awaiting people". ${ }^{30}$ Based on the official 1999 report from Ministry of Labor and Social Security in China, the urban registered unemployment is 5.7 million, and the urban registered unemployment rate is $3.1 \% .^{31}$ However, many studies show the unemployment problems to be more severe than this figure indicates. ${ }^{32}$ It is estimated there are 15 million people,

27 R. G. Wilkinson, 'Income Distribution and Life Expectancy', British Medical Journal, 304 (1992), 165-68; Y. L. Liu, W. C. Hsiao, et al., 'Equity in Health and Health Care: the Chinese Experience', Social Science \& Medicine, 49(10) (1999), 1349-1356.

28 S. Szreter, 'Rapid Economic Growth and "the Four Ds" of Disruption, Deprivation, Disease and Death: Public Health Lessons from Nineteenth-Century Britain for Twenty-FirstCentury China', Tropical Medicine and International Health, 4(2) (1999), 146-152.

29 M. Rosko, and R. Broyles, The Economics of Health Care (Westport, Connecticut, Greenwood Press, Inc., 1988).

30 F. Shan, 'Unemployment in Mainland China: Current Situation and Possible Trends', Issues \& Studies,_32(10) (1996), 75-84.

31 Ministry of Labour and Social Security, Yearbook of China Labour, 1999 (Beijing, China Labour and Social Security Publishing House, 2000).

32 J. C. B. Leung, 'The Political Economy of Unemployment and UnemploymentInsurance in the Peoples-Republic-of-China', International Social Work, 38(2) (1995), 139-149; L. Wong, and N. Kinglun, 'Unemployment and Policy Responses in Mainland China', Issues \& Studies, 33(1) (1997), 43-63; G. P. Mao, and Y. Higano, 'Measurement of Concealed Unemployment in Shanghai', International Regional Science Review, 21(1) (1998), 59-78; E. X. Gu, 'From Permanent Employment to Massive Layoffs: the Political Economy of 'Transitional Unemployment' in Urban China (1993-8)', Economy and Society, 28(2) (1999), 281-299; V. Mok, 'Post-Mao Economic Transition: The Role of Non-State Enterprises', Issues \& Studies, 36(2) (2000), 1-31. 
which is three times higher than the registered unemployment figure, are unemployed, lost their job, or are awaiting for a job in $1999 .^{33}$

Based on a study of 4000 households from 13 cities in six provinces in 2000, as many as $11 \%$ of urban workers had been retrenched, and $53 \%$ of these remained unemployed. The risk of retrenchment was higher for women, the less educated, the low skilled, the middle-aged, and those employed by local government or urban collectives. The duration of unemployment is longer for the unhealthy, the less educated, and woman with young children. ${ }^{34}$ Those people who lost their job not only lost their income, but also lost or partially lost their welfare including health insurance, which made it more difficult for them to access health care services. The frustration and pressure due to the loss of a job also had a potential impact on their health status.

The surplus of the labor force in rural China also became a significant social issue. As described in the previous section, the rural economic reforms have greatly mobilized farmers to improve their productivity. However, the increase of productivity also produced the surplus of labor. It is estimated that about $1 / 3$ of farmers, which is about 150 millions, became surplus labor in rural China. With the economic development in urban China, many farmers moved to the urban area to find better and more profitable jobs. It is estimated that there is about 100-140 million floating population in urban areas since 1997 (which include both people from rural to urban and from one urban to other urban areas). This floating population has become one of major sources of labor for urban development. However, it has also created a series of social problems. They are not integrated into the urban health care system with no health insurance and limited access to community health services. Isolated in the city, casual and commercial sex became very prevalence in this population. They have become a high-risk population of sexual transmitted disease and HIV/AIDS, and the "bridge population" to transmit these diseases to the others.

\section{Demographic Change}

With the birth rate and mortality rate declining and the life expectancy rate increasing, the aging of the population accelerated after the economic reform. The percentage of people over 65 years old had increased from $4.9 \%$ in 1982 to $7.0 \%$ in 2000 (Table 3 in Tables). It estimated this figure would be up to 14\%, which is

33 J. Tang, The Report on China Urban Poverty and the Relapse of Poverty (Beijing, Huaxia Publish House, 2002).

34 S. Appleton, J. Knight, et al., 'Labor Retrenchment in China, Determinants and Consequences', China Economic Review, 13 (2002), 252-275. 
similar to Japan's current status, in 25 years. ${ }^{35}$ Based on the study of National Health Service Survey in 1993, the per capita illness day for the elderly (age 60 and above) is 64 days, which is 3.8 times higher than the general population. ${ }^{36}$ It is expected that chronic diseases as well as disability will be more prevalence in the population. The demand for the health service utilization for these chronic diseases will increase.

The caring system for the elderly has also changed gradually. Traditionally, Chinese had a large family with three or more generations living together with different generations playing different roles in the family. The mid-aged family members acting as careers to their parents. Many grandparents in turn take care responsibility for their grandchildren. With the improvement of living conditions and culture changes, fewer families had more than two generations living together in the same household. Family size reduced from 4.4 persons per household in 1982 to 3.4 persons per household (Table 3 in Tables). The responsibilities of caring for the aged population and children gradually switched from family to the society.

\section{The Change of Social Value, Culture}

After the economic reform, Chinese social values and culture also changed drastically. Before the economic reform, political and moral rewards were the major incentive for people to work for society. After the introduction of market economy, economic incentive becomes the major mechanism of rewarding people's productivity. "Political person" becomes "economic person". Based on the study of the criteria of selecting a spouse, the peoples preference had been shifted from "family political background' and "personal political status" to "better occupation", "high income", and "better housing" (Table 4 in Tables).

The second change is that the collectivism had been weakened and the individualism had been strengthened. The Chinese people used to work collectively and share the responsibility, benefit, and economic gain evenly with his/her colleagues who work in the same working unit, state-owned or collective-owned enterprises, and collective-owned farming community. After the economic reform, individual contribution had been rewarded individually. The personal difference from others had been encouraged by the society.

The third change is that the social capital has been weakened. Traditionally, the Chinese social network was built upon the family ties, relatives and people who come from the same community. After the introduction of market economic, those

35 K. Chen, Aging issue in China: The Problems and Their Solution (Beijing, China Union Medical School Publishing House, 2002).

36 Ministry of Health, Research on National Health Services (Beijing, Ministry of Health, China, 1994). 
traditional relationships are gradually replaced by the relationships of economic ties and sharing common interests. Due to the corruption and inconsistency of government policy, people are less and less trusting of the government. Recent evidence from the developed world suggest that the decline of social capital could have a negative impact on the population's health status. ${ }^{37}$ Changes in social values also increased the cost and difficulties in mobilizing the population for public preventive activities, such as environmental protection, sanitation, and health education. ${ }^{38}$

\section{The Change of Health Related Behaviors}

Key health behaviors such as diet, smoking and drinking have also accompanied economic reform. China's food consumption has changed from traditional low fat, high vegetable diet to "Western-style" high fat, meat based diet. ${ }^{39}$ This is resulting in a disease pattern that is shifting toward the chronic "Western-style" disease pattern. ${ }^{40}$ Such disease patterns are believed to be closely correlated with the over consumption of fatty food, dairy products, sugar, alcohol and tobacco. ${ }^{41}$

China is the largest tobacco producer and consumer in the world with one third of all smokers in the world being Chinese. ${ }^{42}$ Based on China's Second National Survey of Smoking in 1996, the smoking rate was $37.6 \%$ overall, $66.9 \%$ for men and $4.2 \%$ for women. Heavy smokers, those who smoke at least 20 cigarettes per day, have rates of $4.1 \%$ for the total population, $7.5 \%$ for males, and $0.2 \%$ for females. ${ }^{43}$ These rates have been increasing as compared to data from the 1984 National survey and, in addition, the starting age decreased. ${ }^{44}$ It has been predicted

37 I. Kawachi and L. Berkman, 'Social Cohesion, Social Capital, and Health', Social Epidemiology, L. Berkman and I. Kawachi (Oxford, Oxford University Press, 2000), 174-190.

38 Y. Liu, 'Historical Review of Social Mobilization Measures', Strategy and Management, 4 (1999).

39 S. Du, B. Lu, et al., 'A New Stage of the Nutrition Transition in China', Public Health Nutrition, 5(1A) (2002), 169-74.

40 C. J. Smith, '(Over) Eating Success: The Health Consequences of the Restoration of Capitalism in Rural China', Soc. Sci. Med., 37(6) (1993), 761-770.

41 J. Chen, Diet, Life-Style and Mortality in China: A Study of the Characteristics of 65 Chinese Counties (Oxford, Oxford University Press, 1990).

42 T. H. Lam, Y. He, et al., 'Mortality Attributable to Cigarette Smoking in China' $J A M A, 278(18)$ (1997), 1505-08; People's Daily, 'China Faces Hard Job to Control Smoking', People's Daily (China, 2000).

43 G. H. Yang, 1996 National Prevalence Survey of Smoking Pattern (Beijing, China Science and Technology Press, 1997).

44 Yang, (1997). 
that half of male smokers will die between the ages of 35 and $65 .{ }^{45}$ The increase in the already high prevalence of smoking in China shows the urgency of preventing new smokers and also of reducing the number of current smokers.

Sexual freedom, increased promiscuity, economic incentives, mobility of population and increasing disparity between the rich and poor leading to a rise of commercial sex are major factors that drive the rise of Sexual Transmitted Diseases (STD). Based on the government statistic report, the incident rate of gonorrhea increased from 6.84 per 100,000 populations in 1990 to 18.31 per 100,000 populations in 2000 . The incident rate of syphilis also increased from 0.093 per 100,000 populations in 1990 to 4.73 per 100,000 populations in 2000 (Table 5 in Tables). The number of HIV infected persons already reached to 850,000 cases in 2002 based on the government estimation; figures from international organizations are much higher. ${ }^{46}$

\section{Change of Health Care Financing and Health Delivery System}

One of the most striking health care problems is the inequality of access to the services. Based on the rural household survey conducted by the Ministry of Health in 1986, about $29 \%$ were unable to be hospitalized due to unable to afford the high cost of hospitalization. ${ }^{47}$ This figure increased to $64 \%$ in $1998 .^{48}$ The decreased accessibility of health care service is not only influenced by economic and social changes, such as the inequality of income, but also is related to the health care system transition itself, such as the change of health care financing and the reform of health care delivery system to a market oriented system.

45 T. H. Lam, S. Y. Ho, et al., 'Mortality and Smoking in Hong Kong: Case-Control Study of All Adult Death in 1998', BMJ, 323 (2001), 1-6.

46 P. M. Gorbach, C. Ryan, et al., 'The Impact of Social, Economic and Political Forces on Emerging HIV Epidemics', AIDS, 16(Suppl 4) (2002), 35-43.

47 Ministry of Health, Research on National Health Services (Beijing, Ministry of Health, China, 1986).

48 Ministry of Health, Research on National Health Services-An Analysis Report of the Second National Health Services Survey in 1998(I) (Beijing, Ministry of Health, China, 1999). 
Figure 5. Sources of health care financing in China 1990-2000.

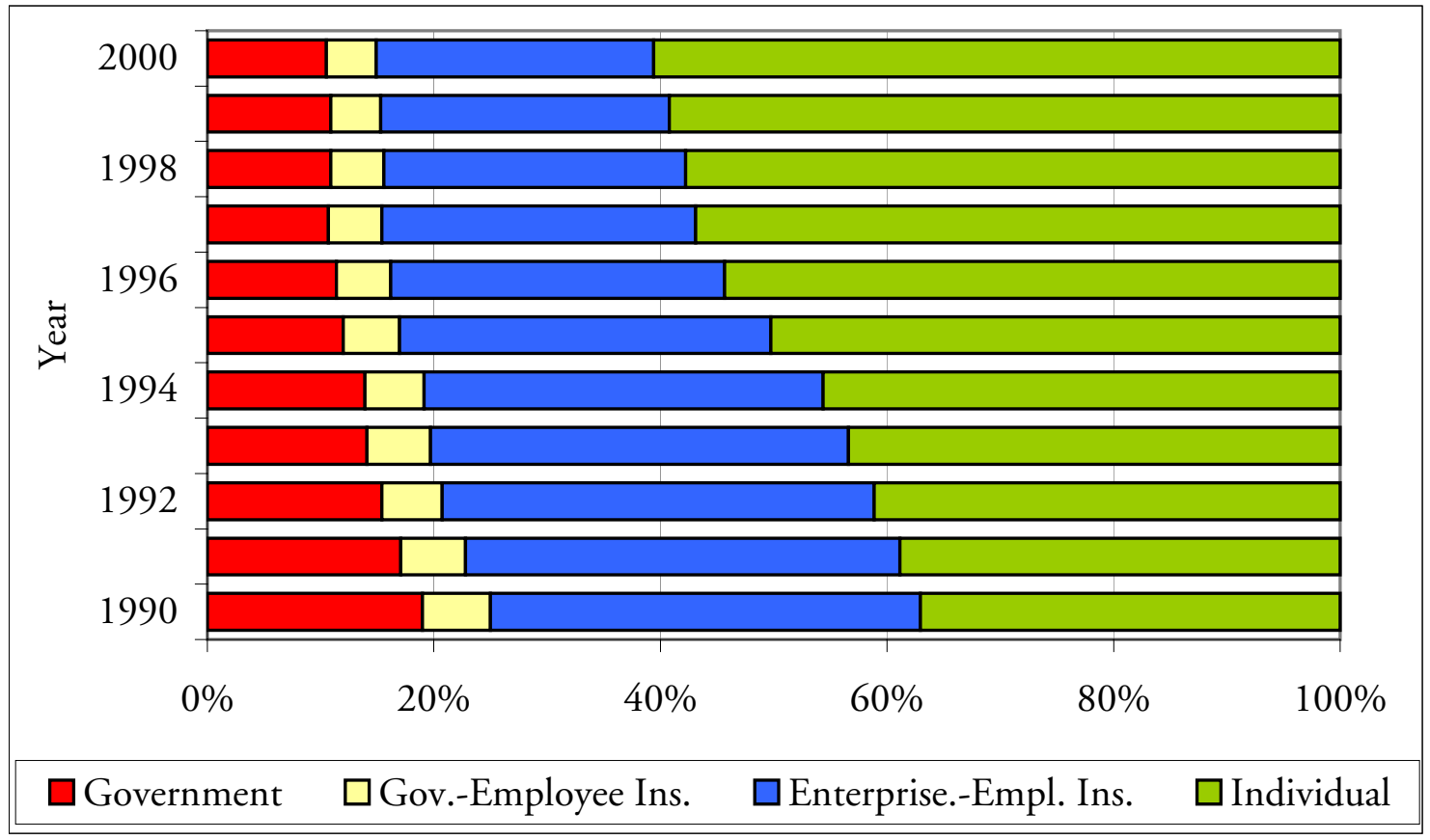

Source: Cai 2002.

\section{Change of Health Care Financing}

There are three major sources of health care financing, the government, the employer, and the individual. All of these three sources increased in terms of the absolutely values of health expenditure during 1990-2000. However, due to the increase of individual expenditure, it is much faster than government and employer's expenditure. The share of individual expenditure in total health expenditure increased from $37 \%$ in 1990 to $61 \%$ in 2000 , while the shares of other resources all declined. The decline of the share of government expenditure for the public is the most stark, almost reduced to the half of its share in 1990 (Figure 5).

The decline of health insurance coverage is considered the major reason for the rapid increase of individual health expenditure. In the urban area, health insurance systems are mainly employment-based schemes (i.e. Government Employee Health Insurance and Enterprise Employee Health Insurance). Increasing unemployment in both the private and public sector has led to a sharp decline in social insurance coverage (Table 6 in Tables). In addition, with the cost containment concern, the originally "free" public health insurance system has been replaced by commerciallike health insurance schemes with a variety of cost sharing mechanisms, such as indemnity, deduction, co-payment, and coinsurance measures. ${ }^{49}$ These cost sharing

49 W. C. Yip and W. C. Hsiao, 'Medical Savings Accounts: Lessons from China', Health Affairs, 16(6) (1997), 244-251; T. W. Hu, M. Ong, et al., 'The Effects of Economic Reform on 
mechanisms also increase the individual health expenditure and financial burden for people using medical services.

Before the economic reform, Cooperative Medical System (CMS) was the insurance scheme in rural China to cover the major health expenditure. Ninety three percent of rural villages were covered by the CMS in $1976 .^{50}$ The major source of funding for this insurance scheme relied on the collective economic, the commune system. However, with the replacement of individual responsible system to the collective economic system, CMS collapsed due to the loss of financial support and political interferences. By the time of 1990 , only $6.1 \%$ of villages have kept the CMS system (Table 7 in Tables) ${ }^{51}$ and only $5 \%$ of rural residents were covered. $^{52}$ Although there were numerous attempts for restoring rural health insurance during 1990s, most of these attempts failed due the lack of policy support, lack of willingness and capacity to pay for the insurance premium by individual farmers, and lack of capacity of the management of CMS. The rural health services are now largely provided by individual rural doctors paid by fee-forservice payment method. Only those patients who have the ability-to-pay for these services are able to access these services. ${ }^{53}$

The decentralization of the government fiscal system also has a potential impact on the inequality of access health care services. As part of the general decentralization of the government authority, the structure of government health care financing was changed so that each level of government was directly responsible for maintaining the health institutions under its administration. ${ }^{54}$ For example, central government finances only the national hospitals, research institutes, and medical schools, which report directly to the central government. Each province or county is responsible for its own public services, including health care education and welfare, thus, a prosperous county may be able to provide generous health care and a poor county may have to settle for less. ${ }^{55}$

Health Insurance and the Financial Burden for Urban Workers in China', Health Economics, 8(4) (1999), 309-321.

50 X. Feng, S. Tang, et al., 'Cooperative Medical Schemes in Contemporary Rural China', Soc. Sci. Med.,_41(8) (1995), 1111-1118.

51 Feng, Tang et al. (1995).

52 X. Gu, G. Bloom, et al., 'Financing Health Care in Rural China: Preliminary Report of A Nationwide Study', Soc. Sci. Med., 36(4) (1993), 385-391.

53 W. C. L. Hsiao, 'The Chinese Health-Care System - Lessons for Other Nations', Social Science of Medicine, 41(8) (1995), 1047-1055.

54 G. E. Henderson, J. S. Akin, et al., 'Trends in Health Services Utilization in Eight Provinces in China, 1989-1993', Soc. Sci. Med., 47(12) (1998), 1957-1971.

55 Hsiao, (1984). 


\section{Reform of Health Care Delivery System}

The diffusion of economic reform has transformed health care institutions from heavily subsidized welfare institutions to marketed oriented cost recovery and surplus/profit driven entities. In order to improve the efficiency and productivity, the government has adopted these following major approaches to reform health care system.

First, the government limited public funds available for health care institutions, covering only basic personnel wages and certain new capital investment, which were about $25-30 \%$ of health institutes' cost, thereby leaving the health institute to recover the other $70-75 \% .^{56}$

Second, the government used different price policies in order to encourage particular patterns of health care usage. Prices for most basic health services have been kept low, based on historical fees set in the 1950s. However, the prices are established higher than their cost for new and high technology services. Hospitals and doctors were also allowed to keep 15-25\% mark up from selling the drugs. ${ }^{57}$ In order to reduce cost and increase competition, the drug distribution system also changed. Hospitals and clinics are allowed to purchase drugs directly from drug companies, factories and retailers with lower prices. This policy has enabled them to make profits from selling drugs. However, hospitals and clinics may purchase low quality drugs in order to earn more or for more commissions to the individuals who is in charge of purchasing drugs on behalf of hospital and clinics. ${ }^{58}$

Third, the government gave health institutes a large degree of financial independence. As in the economic sector, the bonus wage has been introduced as the economic incentives to improve doctors' and other medical staff s productivity. The bonus wage is from the profits of health institutes. There is thus strong incentive for doctors to provide highly profitable services to the patients, such selling more drugs and providing more high-technology services.

Fourth, the government allowed private ownership of health institute and private clinical practices to compete with public-owned health institutes. Private investment in new health institute was promoted by allowing them to charge higher fees than allowed by public-owned institutes. ${ }^{59}$ The services that provided by those private-owned health institute are driven by the demand of health care market.

With all those reform approaches described above, the productivity of health institute, doctors income, health care investment and health care expenditure all

56 Hsiao, (1995).

57 Hsiao, (1995).

58 H. Dong, L. Bogg, et al., 'Drug policy in China: Pharmaceutical Distribution in Rural Areas', Soc. Sci. Med.,_48 (1999), 777-786.

59 Hsiao, (1995) 
increased. Per capita health expenditure increased from 11.4 Yuan in 1978 to 364.2 Yuan in 2000 (Table 8 in Tables). ${ }^{60}$ Cost inflation became another barrier to access to health care services. ${ }^{61}$

\section{The Change of Public Health System}

China has a long history of recognizing that the disease prevention is a very important issue in terms of human survival and socio- economic development. The idea of "prevention is better than cure" comes from the earliest Chinese Medicine treatise, Huangdi Neijing which was written over a period, from 206 B.C. to 8 A.D. ${ }^{62}$

After the Liberation in 1949, in order to put the principle of "preventive service should be the first priority among health services" ${ }^{33}$ into practice, the Chinese government established public health administration agencies as well as the preventive service system called Epidemic Prevention Station system (it was renamed to Center for Disease Control and Prevention) at each administration level. Although public health plays a very important role in controlling communicable disease and improving population health, the total expenditure on public health services provided by EPS/CDC is very limited. Based on estimates from the National Health Account Research Team, the revenues of EPS and other disease control and prevention institutes (the expenditures from all sources on these institution services) increased four-fold from 2027 million Yuan in 1990 to 8150 million Yuan in 1998. Still this was a slight decline as a share of the total health expenditure from $2.36 \%$ t in 1990 to $2.1 \%$ in 1998 (Table 9 in Tables). ${ }^{64}$

Public health institutes, including the EPS, were traditionally financed completely by the government and provided free public health services. ${ }^{65}$ However, after the economic reform, these public health institutes were no longer considered pure welfare entities. The government provides a fixed budget to each public health

60 R. Cai, Developing Health Care System and Improving Health Status. Conference on Macro-Economy and Health (Beijing, China Health Economic Institute, MOH, 2002).

61 X. Z. Liu and W. C. L. Hsiao, 'The Cost Escalation of Social Health-Insurance Plans in China - Its Implication for Public-Policy', Social Science \& Medicine, 41(8) (1995), 1095-1101.

62 Z. Cheng, and Z. Song, Brief Medical History (Beijing, Beijing Medical University and Beijing Union Medical University Joint Publishing House, 1990).

63 S. Huang and S. Lin, Contemporary Chinese Health System (Beijing, China Social Science Publishing House, 1986).

64 G. Liu, Y. Zhao, et al., 'Study on the Allocation for Chinese Health Accounting in Health System', Chinese Journal of Health Economics, 20(2) (2001), 29-33.

65 D. Yu and J. Meng, 'The Study on Financial Operational m Mechanism within Health System', Improving Health Economic Policies (S. C. P. R. Group. Beijing, China Economic Publishing House, 1996), 57-75. 
institute to cover staff salaries and a parts of the services cost. Although certain public health services are still free for the public (paid for by local government), such as the vaccines in EPI, and random monitoring of sanitation in public sites, drinking water and foods, a significant portion of the services were allowed to charge for services, in order to generate additional revenue to compensate shortfall in the government budget. ${ }^{66}$ The results of the National Health Services Survey in $1998^{67}$, which included data from 130 EPSs, showed that only about $38 \%$ of the EPSs' revenue came from the government budget in 1997. Fifty eight percent of the EPSs' revenue came from their service charges, for health services such as physical check-up for people who work in food industries, and health monitoring and inspection (Table 10 in Tables). With these additional charges, the EPSs are able to recover their costs and have an average surplus of about 86,000 Yuan per institute per year.

The positive effect of the fixed government budget for EPSs has increased financial accountability of the institutes, resulting in the reduction of waste. It also gave incentives to EPSs to expand their public health services to new areas and new population groups. Thus they now provide additional services, such as testing the safety of the new construction materials, water purifying devices, and so on, and new immunizations (not included in the EPI program) to cover certain high risk population groups. However, these policies also had negative effects, with high social costs. Since the public health services have been divided into user's charge and non-user's charge categories, it creates incentives for EPSs to over- provide the services that can bring additional revenues to the institutes, such as sanitation inspections (the food industry, restaurants, hotels, and industries which discharge pollutants and have risky working conditions, primary schools, etc. are subject to inspections by EPSs), and to under-provide the services that do not bring additional revenues to the institutes ,such as immunization and monitoring of diseases. ${ }^{68}$

The bonus wage was also introduced into public health system. The amount of bonus wage is linked with the revenues that department could bring by user's charge. Since the services that allow having user's charge are different by department, the amount of bonus varies by $4-5$ times across different departments within EPS/CDC. This economic incentive has distorted performance of various public health activities.

It is estimated that there are about 1.2 million rural doctors and health assistants and 699,000 health posts (some health posts have more than one staff member). The collectives own $41 \%$ of these health posts and the rest of them are owned by

66 X. Liu, 'Financing Reforms of Public Health Services in China: Lessons for other Nations', Social Science \& Medicine, 54(11) (2002), 1691-1698.

67 Ministry of Health, (1999).

68 Liu, (2002). 
individuals. ${ }^{69}$ Their revenues are mainly from the providing of medical services to the patients based on fee-for-service payment method. Although some of rural doctors receive certain fixed amount subsidies from government to conduct essential disease control and prevention programs, and the government still requests rural doctors to play important roles in disease prevention and control, there is no incentive for them to play very active roles in activities for environmental sanitation, vector control, and health education.

\section{The Changes of Population Health Status}

As described above, the rapid economic development and social change produced mixed effects on population health status. On the one hand, the materials prosperity provided the premise to improve population health status. These included the increase of income, better education, better housing and nutrition status, and more and better health care services. On the other hand, several social problems brought on the economic reform have the potential negative impacts on population health. These factors include the income inequalities, unemployment, poverty, floating population issues, the decline of social capital, and decline of access health care services. The current Chinese population health status reflects the results from both contrary effects.

\section{Level of Population Health Status: Mortality and life Expectancy}

Since 1949, Chinese health status has increased dramatically. Mortality decreased from 18 per 1000 in 1950 to 6.4 per 1000 in 2000. The infant mortality rate declined from 196 per 1000 live births in 1950 to 33.1 per 1000 in 2000. Life expectancy increased from 30.5 in 1949 to 71.4 in 2000 (Table 11 in Tables). The attributions of these health status improvements are the rapid economic development, innovative health system development, and massive public health movements.

However, population health improvement has been slowed down recently and is not consistent with the speed of economic development. GDP per capita increased $4 \%$ annually during $1950-1980$ whilst life expectancy increased $2.1 \%$ per year, and infant mortality declined $5.1 \%$ annually at the same period. During 1980-2000, GDP per capita increased $8.3 \%$ annually, almost twice as fast as the speed before 1980. Life expectancy increased only $0.3 \%$ per year, and infant mortality declined

69 Ministry of Health, 2001 Communique of Health System Development Statistics (Beijing, Ministry of Health, China, 2002). 
$1.6 \%$ annually, which is much lower than the speed before $1980 .^{70}$ Other studies also sow that despite rapid economic growth and improvement in literacy rates, the mortality rate for children under the age of five has not changed since $1985^{71}$, the infant mortality rates have remained virtually unchanged and the average life expectancy has changed little since the mid-1980s. ${ }^{72}$

Although it is arguable that there is potential effect of marginal return decline once economic development as well as health status reach to certain levels, the potential negative effects brought on by the rapid economic and social transitions should not be neglected due to this reason.

\section{Distribution of Population Health Status: Inequality of Health Status}

There is also disparity of population health status across the urban and rural, rich and poor in China. Life expectancy is reported to range from 74.5 years in big city areas to 64.5 years in the poorest rural areas. The infant mortality rate is ranged from 15.8 per 1000 life birth in big city areas to 71.8 per 1000 life birth in the poorest rural areas, also with a significant gradient from rich to poor areas. The prevalence of disability also shows a similar pattern; it ranges from 6.3 per 1000 population in big city areas to 12.4 per 1000 population in the poorest rural areas (Table 12 in Tables). ${ }^{73}$

The disparity of population health status has also widened over the course of economic transition. Evidence shows that infant mortality declined by about $4 \%$ in poor provinces while it declined by about 33\% in rich provinces during 1983 and 1993 period. ${ }^{74}$ As an indicator of this gap, the Ratio of Infant Mortality Rate (IMR) between rural and urban areas has increased from 1.67 in 1981 to 1.75 in 1990 and to 2.93 in $1993 .^{75}$

70 A. Hu and L. Hu, China Macro-economy and Health. Conference on Macro-Economy and Health (Beijing, China Health Economic Institute, MOH, 2002).

71 N. Chen, 'Effect of Society and Economy Development on Infant Mortality Rate in China', Health Economics Research, 2 (2003), 9-12.

72 W. C. L. Hsiao and Y. L. Liu, 'Economic Reform and Health - Lessons from China', New England Journal of Medicine, 335(6) (1996), 430-432.

73 Y. L. Liu, K. Rao, et al., 'China: Increasing Health Gaps in a Transitional Economy', Challenging Inequalities in Health: From Ethics to Action, T. Evens, M. Whitehead, F. Diderichsen, A. Bhuiya and M. Wirth (Oxford, Oxford University, 2001), 77-89.

74 Chen, (2003).

75 Liu, Hsiao et al., (1999). 


\section{Structure of Population Health Status: the Leading Causes of Death}

Like many other countries, China has experienced a shift in the leading cause of death from acute infectious diseases to chronic conditions. In the urban area, infectious diseases and pulmonary tuberculosis were the number 2 and 3 leading causes of death in urban China in 1957. These two causes dropped to number 6 and 8 positions before economic reform (1975). By 1993, infectious diseases were no long among first ten leading causes of death in urban China. Instead, cancer, heart disease, and cerebrovascular disease become the first three leading cause of death in 2000 (Table 13 in Tables). The death due to accident, injury, poisoning and mental health disease is also in the raising trend. Rural China also followed urban transition pattern but with slow trend. By 2000, death due to pulmonary tuberculosis is still in the first ten leading cause of death in rural China (Table 14 in Tables).

The health transition depicted above stems from the dramatic decline in fertility (and the resultant change in the age structure of the population) as well as the successful reduction of infectious diseases' morbidity and mortality. It also reflects the results of social changes due to the most recent economic reform in China. Material prosperity due to economic reform played a more important role in the decline of infectious disease, while psychosocial factors, such as stress and anxiety, brought on by the rapid social change may play a more important role on the increase of chronic diseases. ${ }^{76}$ Unhealthy behaviors, such as the excess consumption of fatty foods, dairy products, sugar, alcohol and tobacco also contribute to these health transition. ${ }^{77}$

Due to its potential close relationship with the rapid economic and social change, suicide rates have also caught peoples' attention, although it is not in the list of leading cause of death. It is estimated that there are over 300,000 suicides in China per year, This makes suicide one of the most important causes of death in the country and makes the suicide rate in China one of the highest in the world. ${ }^{78}$

Due to lack of the data prior to 1987, it is difficult to determine whether the suicide rate increased or not with the rapid economic and social transitions. However, researchers believe that many social changes brought on by the rapid economic reform world influence suicide rate, which includes "the major economic losses for individuals and families due to participating in risky ventures or pathological gambling, increasing rates of marital infidelity and divorce, increasing

76 Wilkinson, (1992).

77 Smith, (1993).

78 M. R. Phillips, H. Liu, et al., 'Suicide and Social Change in China', Culture, Medicine and Psychiatry, 23 (1999), 25-50. 
rate of alcohol and drug use, rapidly increasing cost of health care which may make some people not able to afford, weakening the family ties which results in less social support, migrants to urban for temporary work, and increase the social and economic gaps". ${ }^{79}$

\section{Health Related Quality of Life}

The Health Related Quality of Life (HRQoL) represents another dimension of population health status, which has been investigated much less than the length of life. Recently WHO estimated the Disability Adjusted Life Expectancy (DALY), which is one way of measuring quality adjusted life expectancy, for 192 countries. Based on this estimation, Chinese DALY is 61.2 years for male and 63.3 years for female. Comparing to the life expectancy of 68.1 years for male and 71.3 years for female, the life expectancy losses due to low quality of life (as measured by disability here) are 6.9 years for Chinese male and 8 years for Chinese female. These two figures are 5.7 years for Japanese male and 7.1 years for Japanese female. ${ }^{80}$ Both life expectancy and DALY indicator displayed that Chinese health status is lower than Japanese health status in terms of both length of life and quality of life.

Another study from 2000 Beijing Household Health Survey also found that the Chinese HRQoL might be lower than other developed countries. The EQ-5D dimension indicators and EQ-5D visual analog scale (VAS) have been used to measure Chinese quality of life in this study. Age-specific VAS analysis shows that the VAS scores significantly drop in age 30's to 40's in the Chinese population, which is 10 years younger than in the UK population, and 30 years younger than in the Japanese population. This result might imply that the Chinese population might have earlier and longer lower HRQoL lifespan compared to people living in the developed countries. ${ }^{81}$

The results of this study also show that the Chinese population HRQoL is 78.3 measured by the EQ-5D VAS, Pain/Discomfort and Anxiety/Depression are the major problems of Chinese HRQoL. The social determinants such as employment status and property level are the major determinants of overall population HRQoL. If this significant relationship proves to be causal, a greater disparity in Chinese

79 Phillips, Liu et al., (1999).

80 WHO, The World Health Report 2000, Health Systems: Improving Performance (Paris, France, WHO, 2000).

81 H. Wang, 'Variations in Population Health Related Quality of Life and Health Service Utilization in Beijing, China', Department of Population Health Sciences (Madison, University of Wisconsin-Madison, 2002). 
population HRQoL will be expected due to the increase in disparity of wealth and the increase in unemployment associated with rapid economic transition. ${ }^{82}$

\section{The Options of Social Policies in Improving Population Health}

\section{Reestablishing the Social Value of Equity}

After more than 20 years of economic reform, China has successfully transformed its economy from a central planning system to a market oriented economic system. With the economic transition, social values have also changed. "Getting rich first" becomes the most prominent social goal. Disparity in income, as well as the disparity in other aspects of society such as accessing health care and population health, becomes a normal and acceptable phenomenon.

With the widening of social inequality, its negative effects on the social stability as well as population health have emerged, which will in turn restrict the economic and social development. In order to correct these problems brought by on the market-oriented economic system, social value of "equity" should be reinstalled. A sustainable economic and social development has to rely on the balance of "great efficiency" and "reasonable equity". Social value development is the first step of making effective value-based policies to reach this goal. ${ }^{83}$

\section{Integrating Health Improvement Goals into Broad Economic and Social Development Policies}

Population health is the result of the effects of multiple determinants. As discussed in the previous section, many economic and social policies could have the impact on population health. Therefore, it is important to take the goals of health improvement into the consideration while making these economic and social policies.

However, the Ministry of Health $(\mathrm{MOH})$ used to be considered the least powerful Ministry in the government. Based on the existing administration

82 Wang, (2002).

83 M. Whitehead, G. Dahlgren, et al., 'Developing the Policy Response to Inequalities in Health: A Global Perspective', Challenging Inequalities in Health: From Ethics to Action, T. Evens, M. Whitehead, F. Diderichsen, A. Bhuiya and M. Wirth (Oxford, Oxford University, 2001), 309-323. 
structure, the Ministry of Health does not have the authority and capacity to coordinate other sectors to achieve population health goals. The establishment of a permanent joint health committee, which is similar to the Patriot Health Committee, at State Council level might be necessary to take the responsibility to coordinate multiple sectors in terms of improving population health status. (The Patriot Health Campaigns were initiated in 1952. During the Korea War, the Chinese Communist Government was convinced that the United States intended to use biological weapons to spread communicable diseases in order to reduce the strength of the Liberation Army. Patriot Health Campaign Committee was established on March 14, 1952 in order to prevent the outbreak of communicable diseases. This Committee was composed of members from 21 ministries and various unions. These ministries and unions include planning, finance, construction, industries, commerce, agriculture, water resources, chemistry, culture, education, health, environmental protection, security, the military, civil affairs, workers' union, youth union, and the women's union etc. The Committee holds meetings periodically, to set up the agenda for the Campaigns' activities, and to coordinate and assign tasks to each participant ministry or union for certain common goals of improving population health. ${ }^{84}$

\section{Leaning Health Interventions Towards Vulnerable Population}

Competition is the characteristics of the market economy. The winners in this market competition would obtain more resource to enjoy the goods and services that are provided by the market, and thereby enjoy the better life. The losers in this market competition, however, become the vulnerable population and are left out by the market economic system. With little resources, those vulnerable populations would not be able to enjoy the goods and service that provided by the market. Furthermore, vulnerable populations are exposed to much more risks than betteroff populations, such as unhealthy housing, dangerous working conditions,

nutritional deficiencies, more stressful, more smoking and drinking. ${ }^{85}$ The intervention from public sectors should be more leaning towards those vulnerable populations who are left out by the market.

84 H. Chen, Chinese Health Care (Beijing, People's Health Publishing House, 1985).

85 F. Diderichsen, T. Evens, et al., 'The Social Basis of Disparities in Health', Challenging Inequalities in Health: From Ethics to Action, T. Evens, M. Whitehead, F. Diderichsen, A. Bhuiya and M. Wirth (Oxford, Oxford University 2001), 13-23. 


\section{Increasing Health Insurance Coverage}

Health insurance has been used as a unique social welfare measure to redistribution resources from the healthy population to the most needed unhealthy population; to ensure the accessibility to the health care services; to provide the financial risk protection to the patients; and to ensure the services provided by the doctors are the appropriate (cost-effective) services to the patients. However, the coverage of health insurance is still very low, only about $20 \%$ population that has been covered (the coverage rate is $40 \%$ for urban population and $10 \%$ for rural population). How to provide the health insurance for the $80 \%$ uncovered population is a tremendous challenge to the government as well as to the all society.

In October 2002, Government of China, for the first time in its history, announced its willing to set up a subsidy (RMB 20 Yuan $=\$ 2.5$ per person per year) to support a community-based health insurance scheme to cover basic health service for the farmers who are in poor rural areas of China. Although this announcement represents a significant progress in the Government of China's determination to help the poor farmers, the actual establishment of new health financing scheme and improvement of delivery system are left open. The central government will not disburse the subsidy without the lower level government/community prove to a workable model of such insurance schemes. The local government and the communities are in urgent need for technical support to make a new scheme work and to have financial support to test it before they get the subsidy from central government.

\section{Continuing Reforming Health Delivery System}

Due to the market incentives, it is inevitable that health providers will focus on providing more and better services to the people who can afford them. How to ensure the economical disadvantaged population to access basic services is one of critical social problems in the market-oriented society. With the public financial support, health delivery system should take the responsibility to provide low cost or free first aid services to the people who can't afford the expensive services.

\section{Research, Researches, and Research}

It is been joked that every research project will end up with the results of requiring more research. Indeed, the relationships between economic development and social change and population health are very complex. There are causal relationships between economic development and population health in both directions, i.e. the better economy would lead to better population health and better population health 
also lead to better economic development. Most of the evidences that are cited in this study did not address these causal issues. In addition, the determinants of health are numerous, and we are not able to list all of them in this study and we did not attempt to prioritize them. However, all these unsolved issues are very crucial to make concrete interventions. There is a great need to conduct more research to support sound evidence-based policies. For these reasons, we also conclude, as other study, that there is great need to conduct more research in the following two areas: to conduct more research in order to get better understanding the causal relationships between economic development and social change and population health; to conduct more research in order policy makers able to prioritize their intervention policies.

Hong Wang, M.D., Ph.D., is Assistant Professor at the Division of Global Health, Yale School of Public Health, Yale University, New Haven, CT 06511, USA. 


\section{References}

Appleton, S., J. Knight, et al., 'Labor Retrenchment in China, Determinants and Consequences', China Economic Review, 13 (2002), 252-275.

Atlapedia (2002). People's Republic of China, www.atlapedia.com/online/ countries/china.htm.

Cai, R., Developing Health Care System and Improving Health Status. Conference on Macro-Economy and Health (Beijing, China Health Economic Institute, $\mathrm{MOH}, 2002)$.

Chen, H., Chinese Health Care (Beijing, People's Health Publishing House, 1985).

Chen, J., Diet, Life-Style and Mortality in China: A Study of the Characteristics of 65 Chinese Counties (Oxford, Oxford University Press, 1990).

Chen, K., Aging issue in China: The Problems and Their Solution (Beijing, China Union Medical School Publishing House, 2002).

Chen, N., 'Effect of Society and Economy Development on Infant Mortality Rate in China', Health Economics Research, 2 (2003), 9-12.

Cheng, Z. and Z. Song, Brief Medical History (Beijing, Beijing Medical University and Beijing Union Medical University Joint Publishing House, 1990).

China Statistical Bureau, China Statistical Yearbook 1997 (Beijing, China Statistical Publishing House, 1998).

China Statistical Bureau, China Statistical Yearbook 1999 (Beijing, China Statistical Publishing House, 2000).

China Statistical Bureau, China Statistical Yearbook 2000 (Beijing, China Statistical Publishing House, 2001).

Coacy, D. P. and L. Wang, 'Equity, Efficiency, and Labor-Market Reforms in Urban China: The Impact of Bonus Wages on the Distribution of Earnings', China Economic Review, 11 (2000), 213-231.

Diderichsen, F., T. Evens, et al.,'The Social Basis of Disparities in Health', Challenging Inequalities in Health: From Ethics to Action, T. Evens, M. Whitehead, F. Diderichsen, A. Bhuiya and M. Wirth (Oxford, Oxford University, 2001), 13-23.

Dong, H., L. Bogg, et al., 'Drug policy in China: Pharmaceutical Distribution in Rural Areas', Soc. Sci. Med., 48 (1999), 777-786.

Du, S., B. Lu, et al., 'A New Stage of the Nutrition Transition in China', Public Health Nutrition, 5(1A) (2002), 169-74.

Eckaus, R. S., 'Some Consequences of Fiscal Reliance on Extra budgetary Revenues in China', China Economic Review, 14 (2003), 72-88.

Fang, C., X. Zhang, et al., 'Emergence of Urban Poverty and Inequality in China: 
Evidence from Household Survey', China Economic Review, 13 (2002), 430443.

Farrel, P. and V. R. Fuchs, 'Schooling and Health: The Cigarette Connection', Journal of Health Economics, 1 (1982), 217-230.

Feng, X., S. Tang, et al., 'Cooperative Medical Schemes in Contemporary Rural China', Soc. Sci. Med., 41(8) (1995), 1111-1118.

Gorbach, P. M., C. Ryan, et al., 'The Impact of Social, Economic and Political Forces on Emerging HIV Epidemics', AIDS, 16(Suppl 4) (2002), S35-43.

Grogan, C. M., 'Urban Economic Reform and Access to Health Care Coverage in the People's Republic of China', Soc. Sci. Med., 41(8) (1995), 1073-1084.

Grossman, M., 'The Human Capital Model of the Demand for Health', Handbook of Health Economics (Cambridge, MA, National Bureau of Economic Research, Working Paper 7078, 1999).

Gu, E. X., 'From Permanent Employment to Massive Layoffs: the Political Economy of 'Transitional Unemployment' in Urban China (1993-8)', Economy and Society, 28(2) (1999), 281-299.

Gu, X., G. Bloom, et al., 'Financing Health Care in Rural China: Preliminary Report of A Nationwide Study', Soc. Sci. Med., 36(4) (1993), 385-391.

Henderson, G. E., J. S. Akin, et al., 'Trends in Health Services Utilization in Eight Provinces in China, 1989-1993', Soc. Sci. Med., 47(12) (1998), 1957-1971.

House, J. K. and J. M. Lepkowski, 'The Social Stratification of Aging and Health', Journal of Health and Social Behavior, 35 (1994), 213-234.

Hsiao, W. C., 'Transformation of Health Care in China', $N$ Eng J Med., 310 (1984), 932-326.

Hsiao, W. C. L., 'The Chinese Health-Care System - Lessons for Other Nations', Social Science \& Medicine, 41(8) (1995), 1047-1055.

Hsiao, W. C. L. and Y. L. Liu, 'Economic Reform and Health - Lessons from China', New England Journal of Medicine, 335(6) (1996), 430-432.

$\mathrm{Hu}, \mathrm{A}$. and L. Hu, China Macro-economy and Health. Conference on MacroEconomy and Health (Beijing, China Health Economic Institute, $\mathrm{MOH}$, 2002).

$\mathrm{Hu}, \mathrm{T}$. W., M. Ong, et al., 'The Effects of Economic Reform on Health Insurance and the Financial Burden for Urban Workers in China', Health Economics, 8(4) (1999), 309-321.

Huang, S. and S. Lin, Contemporary Chinese Health System (Beijing, China Social Science Publishing House, 1986).

Kawachi, I. and L. Berkman. 'Social Cohesion, Social Capital, and Health', Social Epidemiology, L. Berkman and I. Kawachi (Oxford, Oxford University Press, 2000), 174-190.

Lam, T. H., Y. He, et al., 'Mortality Attributable to Cigarette Smoking in China', JAMA,_278(18) (1997), 1505-08. 
Lam, T. H., S. Y. Ho, et al., 'Mortality and Smoking in Hong Kong: Case-Control Study of All Adult Death in 1998', BMJ, 323 (2001), 1-6.

Leung, J. C. B., 'The Political Economy of Unemployment and UnemploymentInsurance in the Peoples-Republic-of-China', International Social Work, 38(2) (1995), 139-149.

Li, X., 'The Trend and the Strategies of the Development of Urban basic construction', Beijing, Minstry of Construction, www.stats-sd.gov.cn/ cxjs/cjdt/csjj.htm. (1997).

Liu, G., Y. Zhao, et al., 'Study on the Allocation for Chinese Health Accounting in Health System', Chinese Journal of Health Economics, 20(2) (2001), 29-33.

Liu, X., 'Financing Reforms of Public Health Services in China: Lessons for other Nations', Social Science \& Medicine, 54(11) (2002), 1691-1698.

Liu, X. Z. and W. C. L. Hsiao, 'The Cost Escalation of Social Health-Insurance Plans in China - Its Implication for Public-Policy', Social Science \& Medicine, 41(8) (1995), 1095-1101.

Liu, Y., 'Historical Review of Social Mobilization Measures', Strategy and Management, 4 (1999).

Liu, Y. L., W. C. Hsiao, et al., 'Equity in Health and Health Care: the Chinese Experience', Social Science \& Medicine, 49(10) (1999), 1349-1356.

Liu, Y. L., K. Rao, et al.,'China: Increasing Health Gaps in a Transitional Economy', Challenging Inequalities in Health: From Ethics to Action, T. Evens, M. Whitehead, F. Diderichsen, A. Bhuiya and M. Wirth (Oxford, Oxford University, 2001), 77-89.

Long, G., 'The Opportunities and Challenges to the Policy of "Open the Door to the Outside" under the Globalization', The New Stage of China Economy (2002).

Mao, G. P. and Y. Higano, 'Measurement of Concealed Unemployment in Shanghai', International Regional Science Review, 21(1) (1998), 59-78.

Mckinley, T. and L. N. Wang, 'Housing and Wealth in Rural China', China Economic Review, 3(2) (1992), 195-211.

Ministry of Health, Research on National Health Services (Beijing, Ministry of Health, China, 1994).

Ministry of Health, Research on National Health Services (Beijing, Ministry of Health, China, 1986).

Ministry of Health, Research on National Health Services-An Analysis Report of the Second National Health Services Survey in 1998(I) (Beijing, Ministry of Health, China, 1999).

Ministry of Health, 2001 Communique of Health System Development Statistics (Beijing, Ministry of Health, China, 2002).

Ministry of Labour and Social Security, Yearbook of China Labour, 1999 (Beijing, China Labour and Social Security Publishing House, 2000). 
Mok, V., 'Post-Mao Economic Transition: The Role of Non-State Enterprises', Issues \& Studies, 36(2) (2000), 1-31.

Oberschall, A., 'The Great Transition: China, Hungary, and Sociology Exit Socialism into the Market', American Journal of Sociology, 101(4) (1996), 102841.

Patriot Health Campaign Committee, 'Provincial Summaries of "Ninth Five Year Plan" and the Plans of "Tenth Five Year Plan" on Water and Toilet Improvement' (Beijing, 2002).

Peng, R., R. Cai, et al., China Reform: The Edition of Health System Reform (Dalian, Dalian Publishing House, 1992).

People's Daily, 'China Faces Hard Job to Control Smoking', People's Daily (China, 2000).

Phillips, M. R., H. Liu, et al., 'Suicide and Social Change in China', Culture, Medicine and Psychiatry, 23 (1999), 25-50.

Rosko, M. and R. Broyles, The Economics of Health Care (Westport, Connecticut, Greenwood Press, Inc., 1988).

$\mathrm{Ru}, \mathrm{X} ., \mathrm{X} . \mathrm{Lu}$, et al., Blue Book of the Chinese Society (Beijing, Social Sciences Documentation Publishing House, 2003).

Shan, F., 'Unemployment in Mainland China: Current Situation and Possible Trends', Issues \& Studies, 32(10) (1996), 75-84.

Sheng, H., 'The Relationship between Fiscal System Reform and the Stability of Macro-Economy', Market and Stability (S. Zhang, 2001).

Smith, C. J., '(Over)Eating Success: The Health Consequences of the Restoration of Capitalism in Rural China', Soc. Sci. Med., 37(6) (1993), 761-770.

Szreter, S., 'Rapid Economic Growth and "the Four Ds" of Disruption, Deprivation, Disease and Death: Public Health Lessons from NineteenthCentury Britain for Twenty-First-Century China', Tropical Medicine and International Health, 4(2) (1999), 146-152.

Tang, J., The Report on China Urban Poverty and the Relapse of Poverty (Beijing, Huaxia Publish House, 2002).

Wang, H.,'Variations in Population Health Related Quality of Life and Health Service Utilization in Beijing, China', Department of Population Health Sciences (Madison, University of Wisconsin-Madison, 2002).

Whitehead, M., G. Dahlgren, et al., 'Developing the Policy Response to Inequalities in Health: A Global Perspective', Challenging Inequalities in Health: From Ethics to Action, T. Evens, M. Whitehead, F. Diderichsen, A. Bhuiya and M. Wirth (Oxford, Oxford University, 2001), 309-323.

WHO, The World Health Report 2000, Health Systems: Improving Performance (Paris, France, WHO, 2000).

Wilkinson, R. G., 'Income Distribution and Life Expectancy', British Medical Journal, 304 (1992), 165-68. 
Wong, L. and N. Kinglun, 'Unemployment and Policy Responses in Mainland China', Issues \& Studies, 33(1) (1997), 43-63.

$\mathrm{Xu}, \mathrm{A}$. , 'The changes of the criteria of selecting spouse in China', Sociology Research, $6(2000)$.

Yang, G. H., 1996 National Prevalence Survey of Smoking Pattern ( Beijing, China Science and Technology Press, 1997).

Yin, D., 'The Achievement and Its prospect of Chinese Public Health System' (Beijing, Ministry of Health, China, 2000).

Yip, W. C. and W. C. Hsiao, 'Medical Savings Accounts: Lessons from China', Health Affairs, 16(6) (1997), 244-251.

Yu, D. and J. Meng, 'The Study on Financial Operational m

Mechanism within Health System', Improving Health Economic Policies (S. C. P. R. Group. Beijing, China Economic Publishing House, 1996), 57-75.

Zhang, R. and M. S. Tam, 'Changes in Income Distributions in China in the Process of Economic Reform in the 1980s: A Welfare Approach', China Economic Review, 2(1) (1991), 97-114.

Zhang, Y. and F. He, 'System Transition Induced by Fiscal Pressure', From Planning Economy to Market Economy (Beijing, China Finance Publish House, 1998).

Zhao, M. and S. Wang, The research of income inequality and polarization (Beijing, China Economic Publish House, 2002).

Zheng, G., The Transition of China Social Security System and Its Assessment (Beijing, 2002). 


\section{Tables}

Table 1. Per capita annual consumption of major food commodities, during 19811999, China.

\begin{tabular}{lcccccc}
\hline Food commodities & 1981 & 1985 & 1990 & 1995 & 1999 & $\begin{array}{c}\text { 1999 as \% } \\
\text { of } 1981\end{array}$ \\
\hline Urban & & & & & & \\
Grain (kg) & 145.44 & 134.76 & 130.72 & 97.00 & 84.91 & 58.4 \\
Vegetables (kg) & 152.34 & 144.36 & 138.70 & 116.47 & 114.94 & 75.4 \\
Cooking oils (kg) & 4.8 & 5.76 & 6.40 & 7.11 & 7.78 & 162.1 \\
Pork (kg) & 16.92 & 16.68 & 18.46 & 17.24 & 16.91 & 99.9 \\
Beef and Mutton (kg) & 1.78 & 2.04 & 3.28 & 2.44 & 3.09 & 173.6 \\
Poultry (kg) & 1.92 & 3.24 & 3.42 & 3.97 & 4.92 & 256.3 \\
Eggs (kg) & 5.22 & 6.84 & 7.25 & 9.74 & 10.92 & 209.2 \\
Fish and shrimps (kg) & 7.26 & 7.08 & 7.69 & 9.20 & 10.34 & 142.4 \\
Sugar (kg) & 2.88 & 2.52 & 2.14 & 1.68 & 1.81 & 62.8 \\
Liquor (kg) & 4.38 & 7.80 & 9.25 & 9.93 & 9.61 & 219.4 \\
Rural & & & & & & \\
Grain (kg) & 248 & 257.45 & 262.08 & 258.92 & 247.45 & 99.8 \\
Vegetables (kg) & 142 & 131.13 & 134.00 & 104.62 & 108.89 & 76.7 \\
Cooking oils (kg) & 1.96 & 4.04 & 5.17 & 5.80 & 6.17 & 314.8 \\
Meat (kg) & 5.76 & 10.97 & 11.34 & 11.29 & 13.87 & 240.8 \\
Poultry (kg) & 0.25 & 1.03 & 1.26 & 1.83 & 2.48 & 992.0 \\
Eggs (kg) & 0.8 & 2.05 & 2.41 & 3.22 & 4.28 & 535.0 \\
Fish and shrimps (kg) & 0.84 & 1.64 & 2.13 & 3.06 & 3.82 & 454.8 \\
Sugar (kg) & 0.73 & 1.46 & 1.50 & 1.28 & 1.46 & 200.0 \\
Liquor (kg) & 1.22 & 4.37 & 6.14 & 6.53 & 6.98 & 572.1 \\
\hline
\end{tabular}

Sources: China Statistical Yearbook 2000, China Statistical Bureau. 
Table 2. Selected health related socio-economic indicators by provinces in 2001.

\begin{tabular}{|c|c|c|c|c|c|c|c|}
\hline Regions & $\begin{array}{c}\text { Per } \\
\text { capita } \\
\text { GDP } \\
\text { (Yuan) }\end{array}$ & $\begin{array}{l}\% \text { of } \\
\text { urban } \\
\text { popu- } \\
\text { lation }\end{array}$ & $\begin{array}{l}\% \text { of food } \\
\text { expenditure } \\
\text { in total } \\
\text { expenditure }\end{array}$ & $\begin{array}{c}\% \text { of college } \\
\text { students in } \\
\text { population of } \\
\text { age } 6 \text { and } \\
\text { above }\end{array}$ & $\begin{array}{c}\text { Number of } \\
\text { MD per } \\
10,000 \\
\text { population }\end{array}$ & $\begin{array}{c}\text { Industry } \\
\text { waste } \\
\text { processing } \\
\text { rate }(\%)\end{array}$ & \begin{tabular}{|c} 
Tap- \\
water \\
coverage \\
in rural \\
area $(\%)$
\end{tabular} \\
\hline Average & 7543 & 36.2 & 44.2 & 3.8 & 16.5 & 76.1 & 55.1 \\
\hline 11 & 37382 & 88.3 & 42.8 & 11.4 & 30.1 & 95.2 & 99.9 \\
\hline Beijing & 25523 & 77.5 & 36.0 & 17.5 & 37.7 & 91.1 & 97.2 \\
\hline Tianjing & 20154 & 72.0 & 38.7 & 9.4 & 29.1 & 98.7 & 83.0 \\
\hline Zhejiang & 14655 & 48.7 & 39.0 & 3.4 & 16.7 & 89.9 & 83.3 \\
\hline Guangdong & 13730 & 55.0 & 43.5 & 3.9 & 14.6 & 83.0 & 71.1 \\
\hline Jiangsu & 12922 & 41.5 & 41.4 & 4.1 & 15.6 & 90.9 & 77.8 \\
\hline Fujian & 12362 & 41.6 & 46.1 & 3.2 & 12.3 & 84.5 & 65.5 \\
\hline Liaoning & 12041 & 54.2 & 42.4 & 6.5 & 24.2 & 69.7 & 61.7 \\
\hline Shandong & 10465 & 38.0 & 39.2 & 3.6 & 16.4 & 91.6 & 58.3 \\
\hline Heilongjiang & 9349 & 51.5 & 39.9 & 5.1 & 20.9 & 85.4 & 52.5 \\
\hline Hebei & 8362 & 26.1 & 38.6 & 2.9 & 17.0 & 75.6 & 75.9 \\
\hline Xinjiang & 7913 & 33.8 & 45.1 & 5.6 & 22.9 & 65.9 & 66.7 \\
\hline Hubei & 7813 & 40.2 & 46.1 & 4.1 & 17.1 & 76.5 & 48,6 \\
\hline Jielin & 7640 & 49.7 & 41.9 & 5.2 & 22.9 & 59.9 & 37.1 \\
\hline Hainan & 7135 & 40.1 & 53.9 & 3.5 & 15.6 & 83.0 & 48.1 \\
\hline \begin{tabular}{|l|} 
Inner \\
Mongolia \\
\end{tabular} & 6463 & 42.7 & 39.5 & 4.1 & 24.1 & 61.5 & 31.4 \\
\hline Hunan & 6054 & 29.8 & 47.6 & 3.1 & 15.8 & 75.2 & 51.8 \\
\hline Henan & 5924 & 23.2 & 45.4 & 2.9 & 11.6 & 77.6 & 47.5 \\
\hline Qinghai & 5735 & 34.8 & 47.1 & 3.6 & 18.3 & 57.0 & 56.9 \\
\hline Chongqing & 5654 & 33.1 & 49.4 & 3.0 & 14.5 & 79.0 & 57.1 \\
\hline Shanxi & 5460 & 34.9 & 42.9 & 3.7 & 26.5 & 58.3 & 75.0 \\
\hline Ningxia & 5340 & 32.4 & 42.7 & 4.1 & 18.7 & 40.2 & 29.0 \\
\hline Tibet & 5307 & 18.9 & 62.4 & 1.5 & 19.2 & 44.7 & 10.0 \\
\hline Sichuan & 5250 & 26.7 & 50.9 & 2.7 & 15.1 & 65.7 & 40.3 \\
\hline Anhui & 5221 & 27.8 & 48.2 & 2.5 & 11.3 & 88.6 & 28.1 \\
\hline Jiangxi & 5221 & 27.7 & 48.5 & 2.8 & 12.7 & 61.8 & 39.6 \\
\hline Shanxi (Xian) & 5024 & 32.3 & 39.4 & 4.5 & 18.0 & 60.4 & 34.4 \\
\hline Yunnan & 4866 & 23.4 & 53.4 & 2.2 & 14.5 & 61.9 & 54.7 \\
\hline Guangxi & 4668 & 28.2 & 48.2 & 2.6 & 12.8 & 76.3 & 50.7 \\
\hline Gansu & 4163 & 24.0 & 43.9 & 2.9 & 14.9 & 56.8 & 32.5 \\
\hline Guizhou & 2895 & 23.9 & 55.5 & 2.2 & 12.2 & 51.9 & 44.2 \\
\hline
\end{tabular}

Source: $\mathrm{Ru}$, Lu et al. 2003Table 3. Household size, median age and age composition during 1953-2000. 
Table 3. Household size, median age and age composition 1953-2000.

\begin{tabular}{cccccc}
\hline \multirow{2}{*}{ Year } & \multirow{2}{*}{ Household size } & \multirow{2}{*}{ Household median age } & \multicolumn{3}{c}{ Age composition (\%) } \\
\hline 1953 & 4.33 & 21.7 & 36.28 & 59.34 & 65 and over \\
1964 & 4.43 & 20.2 & 40.69 & 55.75 & 4.41 \\
1982 & 4.41 & 22.9 & 33.59 & 61.5 & 4.96 \\
1990 & 3.96 & 25.25 & 27.69 & 66.74 & 5.57 \\
2000 & 3.44 & 30.08 & 22.89 & 70.15 & 6.96 \\
\hline
\end{tabular}

Sources: China Statistical Yearbook 2001, China Statistical Bureau.

Table 4. The changes of the criteria of selecting spouse in China.

\begin{tabular}{lcccc}
\hline \multirow{2}{*}{ Criteria } & \multicolumn{4}{c}{ Unit: percentage of population } \\
\cline { 2 - 5 } & $\mathbf{1 9 4 8} \mathbf{6 6}$ & $\mathbf{1 9 6 7} \mathbf{7 6}$ & $\mathbf{1 9 7 7} \mathbf{8 6}$ & $\mathbf{1 9 8 7} \mathbf{9 6}$ \\
\hline Family political background and social & 26.6 & 28.8 & 12.65 & 15.56 \\
relationship & & & & \\
Personal political status & 30.5 & 23.5 & 15.5 & 13.9 \\
Education & 10.6 & 11.7 & 12.6 & 25.3 \\
Occupation & 17.8 & 25.8 & 28.2 & 40.7 \\
Income & 20.1 & 27.5 & 27 & 34.9 \\
Housing & 16.4 & 27.7 & 33.1 & 37.2 \\
Health status & 62.6 & 68 & 58 & 60.4 \\
Height & 7.6 & 9.4 & 13.8 & 17.3 \\
Appearance & 13.2 & 22.2 & 24 & 28.8 \\
Temperament and culture & 9.5 & 10.2 & 11.3 & 19 \\
Moral standing: veracity and reliable & 63.3 & 61.4 & 53.5 & 42.3 \\
Gentle or femininity & 32.3 & 38 & 36.4 & 39.6 \\
Mature and responsible & 5.8 & 11.1 & 13.1 & 18.1 \\
Common ideality & 15.5 & 17.9 & 12.2 & 12.9 \\
Acceptable personal characters and temper & 39 & 46.5 & 47.3 & 51.1 \\
\hline
\end{tabular}

Source: $\mathrm{Xu}, 2000$. 


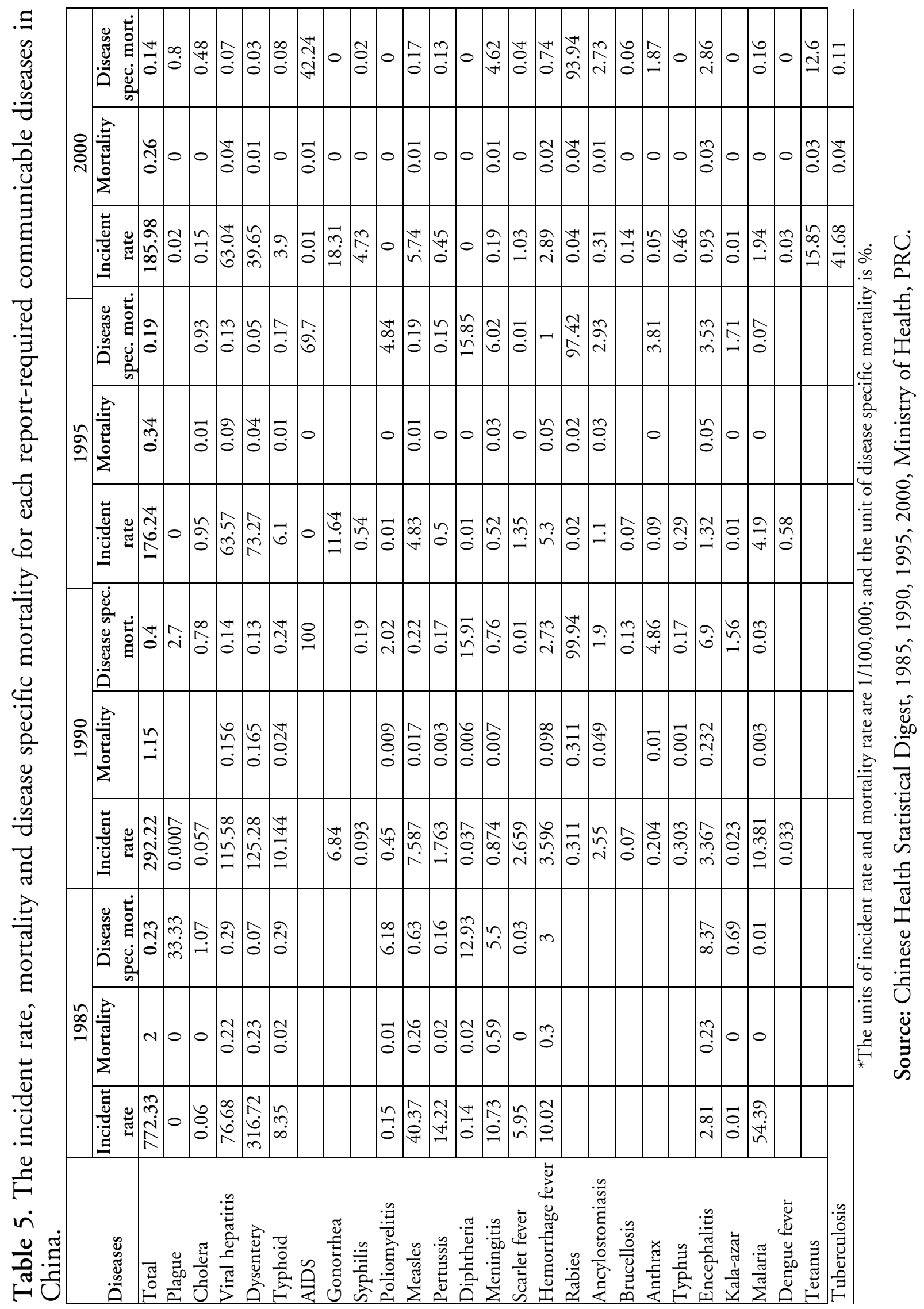


Table 6. The urban health insurance's coverage and its expenditure during 1988-1998.

\begin{tabular}{lccccc}
\hline Year & $\begin{array}{c}\text { Enrolled } \\
\text { population } \\
(\mathbf{1 0 0} \text { million) }\end{array}$ & $\begin{array}{c}\text { Total medical } \\
\text { expenditure (100 } \\
\text { million Yuan) }\end{array}$ & $\begin{array}{c}\text { Per capita } \\
\text { medical } \\
\text { expenditure }\end{array}$ & $\begin{array}{c}\text { The increase rate } \\
\text { of per capita } \\
\text { expenditure (\%) }\end{array}$ & $\begin{array}{c}\text { The increase } \\
\text { of coverage } \\
\text { rate (\%) }\end{array}$ \\
\hline 1988 & 1.5304 & 183.2 & & & \\
1989 & 1.56957 & 224.4 & & 19.2 & 2.6 \\
1990 & 1.60387 & 268.6 & & 16.8 & 2.2 \\
1991 & 1.65737 & 315 & & 13.8 & 2.3 \\
1992 & 1.70444 & 372.7 & & 15.3 & 2.8 \\
1993 & 1.72732 & 461 & 267 & 21.9 & 1.3 \\
1994 & 1.7523 & 561.2 & 321 & 20.2 & 1.4 \\
1995 & 1.76821 & 660.7 & 374 & 16.5 & 0.9 \\
1996 & 1.77746 & 737 & 415 & 11 & 0.5 \\
1997 & 1.78175 & 797.1 & 447 & 7.7 & 0.2 \\
1998 & 1.77815 & 834 & 469 & 4.9 & -0.8 \\
\hline
\end{tabular}

Source: Zheng, 2002.

Table 7. The coverage of Co-operative Medical System (CMS) in rural China during 1976-1990.

\begin{tabular}{lccc}
\hline Year & Villages & Village with CMS & \% of villages with CMS \\
\hline 1976 & 677,834 & 629,708 & 92.9 \\
1978 & 685,994 & 562,515 & 82.0 \\
1980 & 702,908 & 483,601 & 68.8 \\
1982 & 717,665 & 378,927 & 52.8 \\
1984 & 715,265 & 54,100 & 7.6 \\
1986 & 738,139 & 35,649 & 4.8 \\
1988 & 734,095 & 41,940 & 5.7 \\
1990 & 749,963 & 45,491 & 6.1 \\
\hline
\end{tabular}

Source: Feng, Tang et al. 1995. 
Table 8. Total health expenditure and is composition in total GDP during 1978-2000.

\begin{tabular}{lcccccc}
\hline Year & $\begin{array}{c}\text { Total GDP } \\
\text { 100m Yuan }\end{array}$ & $\begin{array}{c}\text { Annual } \\
\text { increase } \\
(\%)\end{array}$ & $\begin{array}{c}\text { Total Health } \\
\text { expenditure } \\
\text { 100m Yuan }\end{array}$ & $\begin{array}{c}\text { Annual } \\
\text { increase } \\
(\%)\end{array}$ & $\begin{array}{c}\text { \% GDP } \\
(\%)\end{array}$ & $\begin{array}{c}\text { Per capita } \\
\text { expenditure } \\
\text { Yuan }\end{array}$ \\
\hline 1978 & 3624.1 & 11.7 & 110.2 & & 3.0 & 11.4 \\
1979 & 4038.2 & 7.7 & 126.2 & 10.6 & 3.1 & 12.9 \\
1980 & 4517.8 & 7.8 & 143.2 & 9.4 & 3.2 & 14.5 \\
1981 & 4862.4 & 5.3 & 160.2 & 9.3 & 3.3 & 16.0 \\
1982 & 5294.7 & 9.0 & 177.5 & 11.0 & 3.4 & 17.5 \\
1983 & 5934.5 & 10.9 & 207.4 & 15.6 & 3.5 & 20.1 \\
1984 & 7171.0 & 15.2 & 242.1 & 11.3 & 3.4 & 23.1 \\
1985 & 8964.4 & 13.5 & 279.0 & 4.6 & 3.1 & 26.4 \\
1986 & 10202.2 & 8.9 & 315.9 & 8.3 & 3.1 & 29.4 \\
1987 & 11962.5 & 11.6 & 379.6 & 14.3 & 3.2 & 34.7 \\
1988 & 14928.3 & 11.3 & 488.0 & 14.6 & 3.3 & 44.0 \\
1989 & 16909.2 & 4.1 & 615.5 & 15.9 & 3.6 & 54.6 \\
1990 & 18547.9 & 3.8 & 743.0 & 14.3 & 4.0 & 65.0 \\
1991 & 21617.8 & 9.2 & 888.6 & 12.0 & 4.1 & 76.7 \\
1992 & 26638.1 & 14.2 & 1090.7 & 13.8 & 4.1 & 93.1 \\
1993 & 34634.4 & 13.5 & 1370.4 & 9.7 & 4.0 & 115.6 \\
1994 & 46759.4 & 12.7 & 1768.6 & 7.7 & 3.8 & 147.6 \\
1995 & 58478.1 & 10.5 & 2257.8 & 12.8 & 3.9 & 186.4 \\
1996 & 67884.6 & 9.6 & 2857.2 & 19.5 & 4.2 & 233.5 \\
1997 & 74462.6 & 8.8 & 3384.9 & 17.6 & 4.5 & 273.8 \\
1998 & 78345.2 & 7.8 & 3776.5 & 14.3 & 4.8 & 302.6 \\
1999 & 82067.5 & 7.1 & 4178.6 & 13.2 & 5.1 & 331.9 \\
2000 & 89403.6 & 8.0 & 4764.0 & 13.0 & 5.3 & 376.4 \\
\hline
\end{tabular}

Source: Cai, 2002.

Table 9. The Epidemic Prevention Station and other prevention institute's revenues during 1990-1998 (in Million Yuan).

\begin{tabular}{lccc}
\hline Year & Total health expenditure & EPSs services expenses & $\begin{array}{c}\text { \% out of total health } \\
\text { expenditure }\end{array}$ \\
\hline 1990 & 86,066 & 2,027 & 2.36 \\
1991 & 99,390 & 2,270 & 2.28 \\
1992 & 120,154 & 2,657 & 2.21 \\
1993 & 150,100 & 3,390 & 2.26 \\
1994 & 194,035 & 4,222 & 2.18 \\
1995 & 239,540 & 5,030 & 2.10 \\
1996 & 295,716 & 5,935 & 2.01 \\
1997 & 343,561 & 7,394 & 2.15 \\
1998 & 388,460 & 8,150 & 2.10 \\
\hline
\end{tabular}

Source: Liu, 2002. 
Table 10. Epidemic Prevention Station's Revenue and Expenditures in 1997.

\begin{tabular}{lcc} 
Category & $\begin{array}{c}\text { Revenues/expenses } \\
\text { (Thousand Yuan) }\end{array}$ & Percentage (\%) \\
\hline Total Revenue & 2400.0 & \\
Government Budget & 684.0 & 28.5 \\
Special Funds & 220.0 & 9.2 \\
Revenue from service charge & 1390.0 & 57.0 \\
Physical check-up & 303.0 & $21.8^{*}$ \\
Health monitoring and inspection & 363.0 & $26.1^{*}$ \\
Other health services & 345.0 & $24.8^{*}$ \\
& & \\
Total Expenditure & 2314.0 & \\
Staff salaries & 778.0 & 33.6 \\
Drugs & 199.0 & 9.0 \\
Repair cost & 138.0 & 6.0 \\
Service cost & 547.0 & 23.6 \\
Equipment purchasing & 210.0 & 9.1 \\
\hline
\end{tabular}

*These percentage is based on the revenue from service charge as $100 \%$

Source: Liu, 2002.

Table 11. Mortality, infant mortality, and life expectancy during 1949-2000.

\begin{tabular}{cccccccc}
\hline Year & $\begin{array}{c}\text { GDP per } \\
\text { capita } \\
\text { (Chinese } \\
\text { Yuan) }\end{array}$ & $\begin{array}{c}\text { Mortality } \\
\mathbf{1 / 1 0 0 0} \\
\text { population } \\
\text { ) }\end{array}$ & $\begin{array}{c}\text { Annual } \\
\text { decline }\end{array}$ & $\begin{array}{c}\text { Infant Mortality } \\
\text { live birth }\end{array}$ & $\begin{array}{c}\text { Life expectancy } \\
\text { decline }\end{array}$ & (Years) & Annual decline \\
\hline 1949 & & 20 & & 265 & & 30.5 & \\
1950 & $119^{*}$ & 18 & -2 & 195 & -70 & 40.8 & 10.3 \\
1955 & 150 & 12.3 & -1.14 & 179 & -3.2 & 44.6 & 0.76 \\
1960 & 218 & 25.4 & 2.62 & 121 & -11.6 & 49.5 & 0.98 \\
1965 & 240 & 9.5 & -3.18 & 81 & -8 & 59.6 & 2.02 \\
1970 & 275 & 7.6 & -0.38 & 61 & -4 & 63.2 & 0.72 \\
1975 & 327 & 7.32 & -0.06 & 51 & -2 & 65.8 & 0.52 \\
1980 & 460 & 6.34 & -0.20 & 47 & -0.8 & 67.8 & 0.4 \\
1985 & 853 & 6.78 & 0.09 & 42 & -1 & 69.4 & 0.32 \\
1990 & 1634 & 6.67 & -0.02 & 38 & -0.8 & 70.9 & 0.3 \\
1995 & 4854 & 6.57 & -0.02 & 36.4 & -0.32 & & \\
2000 & 7078 & 6.43 & -0.03 & 33.1 & -0.66 & 71.8 & 0.09 \\
\hline
\end{tabular}

*1952 data

Source: Yin, 2000. 
Table 12. Socio-economic and health indicators in cities by size and rural counties by income level, in China 1993.

\begin{tabular}{lccccccc}
\hline \multirow{2}{*}{ Indicators } & \multicolumn{3}{c}{ Urban } & \multicolumn{5}{c}{ Rural } \\
\cline { 2 - 8 } & \multicolumn{1}{c}{ Big-city Mid-city } & Sm-city & Cnty 1 & Cnty 2 & Cnty 3 & Cnty 4 \\
\hline GDP per capita (yuan) & 5,002 & 4,070 & 3,040 & 2,523 & 1,305 & 939 & 664 \\
$\begin{array}{l}\text { Income per capita (yuan) } \\
\text { Population in agriculture }\end{array}$ & 2,291 & 1,947 & 1,158 & 927 & 677 & 561 & 441 \\
(percent) & n.a. & n.a. & n.a. & 81 & 89 & 91.5 & 95.2 \\
$\begin{array}{l}\text { Rate of illiteracy and semi- } \\
\text { illiteracy (percent) }\end{array}$ & 9.6 & 14.8 & 14.2 & 26.4 & 26.8 & 28.1 & 50.7 \\
Life expectancy (years) & 74.5 & 71.3 & 70.0 & 71.0 & 69.0 & 68.3 & 64.5 \\
$\begin{array}{l}\text { Infant mortality rate (per 1000 } \\
\text { life births) }\end{array}$ & 15.8 & 17.1 & 30.1 & 29.3 & 34.5 & 44.2 & 71.8 \\
$\begin{array}{l}\text { Prevalence of disability (per } \\
\text { 1000) }\end{array}$ & & & & & & & \\
Female & 6.4 & 7.5 & 8.5 & 10.6 & 10.8 & 11.5 & 12.5 \\
Male & 6.3 & 7.6 & 9.5 & 9.9 & 10.3 & 12.3 & 12.4 \\
\hline
\end{tabular}

Source: Liu, Rao et al., 2001. 
Table 13. First ten leading causes of death in urban China in selected years.

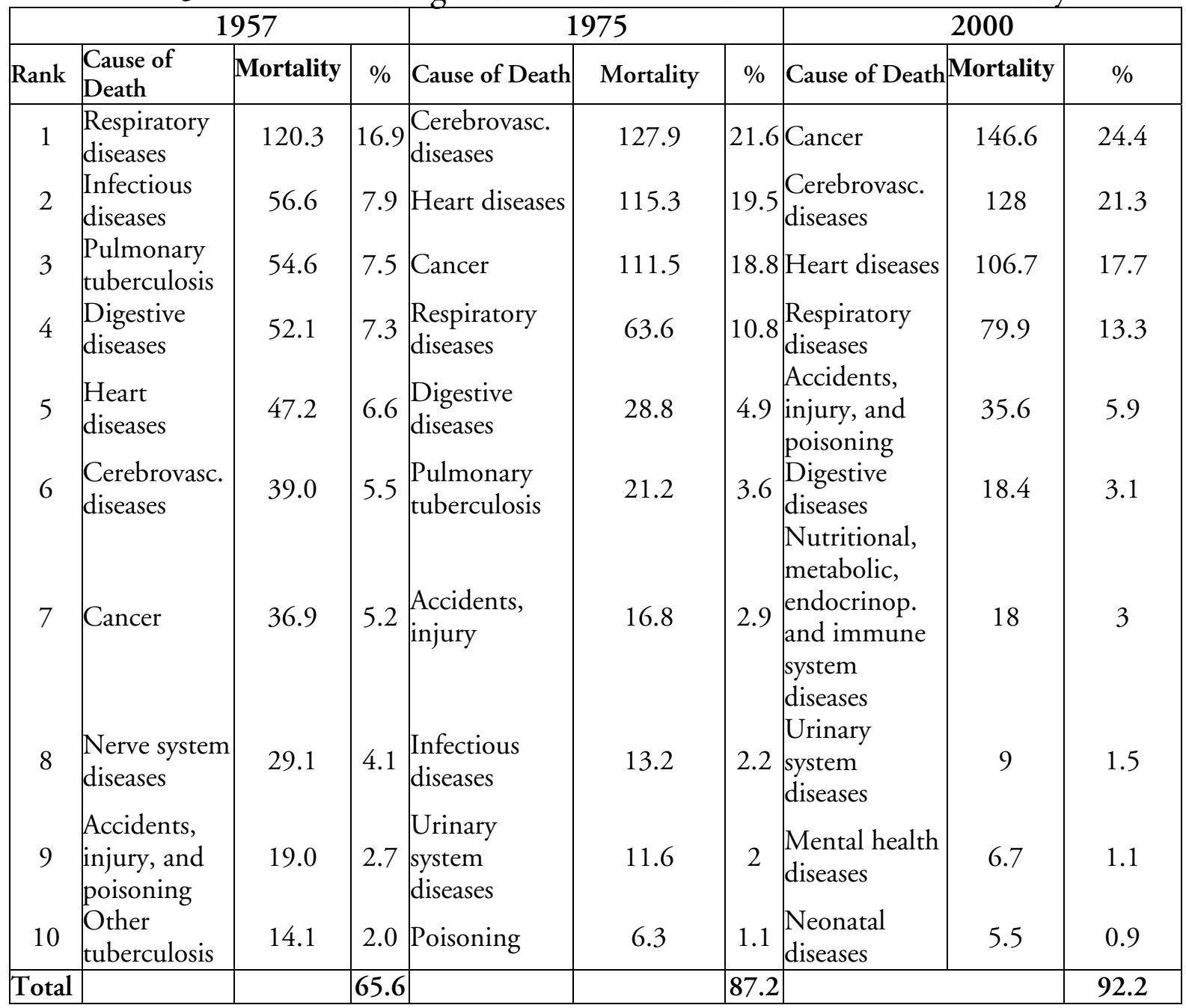

*The unit of mortality is $1 / 100,000$

Source: Chinese Health Statistical Digest, 1985, 2000, Ministry of Health, PRC. 
Table 14. First ten leading causes of death in rural China in selected years.

\begin{tabular}{|c|c|c|c|c|c|c|}
\hline \multirow{2}{*}{ Rank } & \multicolumn{3}{|c|}{1975} & \multicolumn{3}{|l|}{2000} \\
\hline & Cause of Death & Mortality & $\%$ & Cause of Death & Mortality & $\%$ \\
\hline 1 & Heart diseases & 123.2 & 18.0 & Respiratory diseases & 142.2 & 23.1 \\
\hline 2 & Cancer & 119.6 & 17.5 & $\begin{array}{l}\text { Cerebrovascular } \\
\text { diseases }\end{array}$ & 115.2 & 18.4 \\
\hline 3 & Cerebrovascular diseases & 92.3 & 13.5 & Cancer & 112.6 & 18.4 \\
\hline 4 & Respiratory diseases & 88.2 & 12.9 & Heart diseases & 73.4 & 12.4 \\
\hline 5 & Digestive diseases & 46.3 & 6.8 & $\begin{array}{l}\text { Accidents, injury, and } \\
\text { poisoning }\end{array}$ & 64.9 & 11.0 \\
\hline 6 & Pulmonary tuberculosis & 32.6 & 4.8 & Digestive diseases & 23.9 & 4.0 \\
\hline 7 & Accidents, injury & 24.3 & 3.6 & Urinary system diseases & 9.3 & 1.5 \\
\hline 8 & Infectious diseases & 23.8 & 3.5 & Pulmonary tuberculosis & 7.4 & 1.2 \\
\hline 9 & Neonatal diseases & 1194.8 & 2.7 & Neonatal diseases & 697.1 & 1.1 \\
\hline 10 & Urinary system diseases & 10.2 & 1.5 & $\begin{array}{l}\text { Nutritional, metabolic, } \\
\text { endocrinopathic, and } \\
\text { immune system diseases }\end{array}$ & 6.8 & 1.1 \\
\hline Total & $\bullet$ & & 84.7 & & & 91.5 \\
\hline
\end{tabular}

*The unit of mortality is $1 / 100,000$

Source: Chinese Health Statistical Digest, 1985, 2000, Ministry of Health, PRC. 